EM

\title{
RELAÇÕES DA PRODUÇÃO E INSTALAÇÃO DE POÇOS NO CANTO DO AMARO COM INDICADORES ECONÔMICOS DO MUNIḈPIO DE MOSSORÓ-RN
}

\author{
RELATIONS OF THE PRODUCTION AND INSTALLATION OF WELLS IN \\ CANTO DO AMARO WITH ECONOMIC INDICATORS OF THE MUNICIPALITY \\ OF MOSSORÓ-RN
}

\author{
João Paulo Silva dos SANTOS ${ }^{1}$ \\ Marco Antonio DIODATO ${ }^{2}$ \\ Alexsandra Ferreira GOMES ${ }^{3}$
}

\begin{abstract}
Resumo: O petróleo está sempre relacionado com a dinâmica econômica das regiões onde ele é extraído, processado, transportado e revendido. A partir de 1975, a Petrobras iniciou a perfuração de poços no município de Mossoró. No campo do Canto do Amaro a descoberta de petróleo foi em 1985, por meio da perfuração do poço 1-CAM-1-RN. Até 2015, no campo, tinham sido perfurados 1.837 poços. A proposta deste artigo é identificar possíveis relações entre as variações da produção e da instalação de poços com indicadores econômicos do município, entre 1999 e 2015. Os dados e as análises da produção e da instalação dos poços foram comparados com os registros referentes ao recebimento de royalties, ao PIB per capita da população, ao número de pessoas ocupadas assalariadas, ao salário médio mensal e a quantidade de empresas ativas. Dessa forma, buscou-se alcançar um melhor entendimento sobre a influência das variações da produção e da instalação de poços, no Canto do Amaro, em alguns dos indicadores econômicos. É possível verificar similaridades nas oscilações da produção e da instalação de novos poços com os indicadores econômicos determinados, no entanto, elas não são consideráveis para exercerem influência direta nas flutuações dos indicadores considerados.
\end{abstract}

Palavras-Chave: Petróleo, Produção, Poços, Indicadores econômicos, Mossoró.

\begin{abstract}
Oil is always related to the economic dynamics of the regions where it is extracted, processed, transported and resold. Since 1975, Petrobras has started to drill wells in the municipality of Mossoró. In the Canto do Amaro field, the oil discovery was made in 1985 by drilling well 1-CAM1-RN. By 2015, in the field, 1.837 wells had been drilled. The purpose of this paper is to identify possible relationships between production and well variations with municipal economic indicators between 1999 and 2015. The data and analyzes of well production and installation will be compared with the records regarding the receipt of royalties, the per capita GDP of the population, the number of employed persons employed, the average monthly salary and the number of active companies. In this way, we intend to reach a better understanding of the influence of the variations of the production and the installation of wells, in Canto do Amaro, in some of the economic indicators. It is possible to verify similarities in the oscillations of the production and the installation of new wells with the determined economic indicators. However, they are not large enough to exert direct influence on the fluctuations of the indicators considered.
\end{abstract}

Keywords: Petroleum, Production, Wells, Economic Indicators, Mossoró.

\footnotetext{
${ }^{1}$ Licenciado em Geografia. Doutorando em Estudos Urbanos e Regionais da Universidade Federal do Rio Grande do Norte (UFRN). E-mail: joaozxz@yahoo.com.br

${ }^{2}$ Graduado em Engenharia Florestal e Doutor em Ciências Biológicas pela Universidade Federal do Paraná (UFPR). Professor associado da Universidade Federal Rural do Semi-Árido (UFERSA). E-mail: madio61@gmail.com

${ }^{3}$ Graduada em Tecnologia em Informática pelo Instituto Federal de Educação, Ciência e Tecnologia RN (CEFET/RN). Mestre em Ciências da Computação pela UERN/UFERSA. Professora assistente da Universidade do Estado do Rio Grande do Norte (UERN). Email: alexsandrafg@gmail.com
} 
EM

\section{Introdução}

O petróleo, como commodity base da atual matriz energética mundial, está sempre relacionado com a dinâmica econômica das regiões onde ele é extraído, processado, transportado e revendido. Além da sua importância energética, materiais indispensáveis para a sociedade contemporânea, como combustíveis, plásticos, solventes, fertilizantes, borrachas sintéticas e medicamentos são produzidos por meio do seu processamento (FARIAS, 2008). O mineral é uma mistura de hidrocarbonetos originada na decomposição de matéria orgânica devido a ação de bactérias, em ambientes com baixas quantidades de oxigênio. No decorrer do tempo geológico, o produto desse processo, acumulou-se no fundo dos oceanos, mares e lagos e foi exposto aos movimentos da crosta terrestre, tornando-se uma substância oleosa. Atualmente, o petróleo pode ser encontrado em bacias sedimentares com características distintas, principalmente as formadas por camadas porosas de areia, arenitos ou de formações calcárias (ANEEL, 2005).

No Rio Grande do Norte, o padre Florêncio Gomes foi o primeiro a verificar a existência de petróleo, no final do século XIX, no município de Apodi. Em 1922, o cientista John Casper Branner demonstrou a possibilidade da existência do minério na região geográfica de Mossoró. Em 1956, a Petróleo Brasileiro S.A. (Petrobras) realizou a primeira perfuração no Rio Grande do Norte. O local escolhido foi a região da Gangorra, no município de Grossos. O resultado da sondagem foi a identificação de petróleo e gás natural, mas foi decretada a inviabilidade econômica da extração. Em 1973, a empresa identificou petróleo em águas rasas, dos municípios de Macau e Guamaré onde, em 1975, o primeiro poço de petróleo no estado foi posto em funcionamento (GURGEL, et al., 2013).

A partir de 1975, iniciou-se a perfuração de poços no município de Mossoró, mas nenhum apresentou viabilidade para a exploração. Essa condição foi modificada em 1979. Nesse ano um poço, perfurado pela Companhia de Pesquisa de Recursos Minerais (CPRM), para abastecer as piscinas de um hotel, jorrou uma substância líquida composta de água e petróleo. A partir disso, o poço perfurado no hotel, denominado de 9-MO-14-RN, iniciou o período de extração do mineral nas terras do Rio Grande do Norte (ROCHA, 2005).

Durante a década de 1980, as perfurações de poços terrestres foram intensificadas nos municípios de Mossoró, Areia Branca, Macau e Alto do Rodrigues. Em um contínuo avanço da exploração do petróleo, em 2003, haviam 4.664 poços produtores no Rio Grande do Norte, dando ao estado uma posição de destaque nacional como o maior produtor de petróleo em terra e o segundo em produção marítima (GURGEL, et al., 2013).

No campo do Canto do Amaro, a descoberta de petróleo ocorreu em 1985, por meio da perfuração do poço 1-CAM-1-RN. Antes disso, entre os anos de 1980 e 1983, já havia ocorrido a perfuração de cinco poços na área geográfica do campo (1-MO-0021-RN, 1-BVS0002-RN, 1-SU-0001-RN, 1-LA-0001-RN, 1-RAP-0001-RN), mas não foram encontrados indícios de petróleo. A partir de 1986, a perfuração e instalação de poços no Canto do Amaro foi intensificada. Em 2014, o Canto do Amaro foi o campo com maior número de poços produtores no Brasil, totalizando 1.115 (PETROBRAS, 2014). Até o ano de 2015 tinham sido perfurados 1.837 poços. Em janeiro de 2016, haviam 1.038 poços produtores e 432 poços injetores, totalizando 1.470 poços em operação (ANP, 2016).

Em Mossoró, a Petrobras instalou-se em 1980, mas somente em 1990 a empresa construiu sua atual sede, em uma área de 40 hectares, no bairro Sumaré (ROCHA, 2005). Dessa forma, o município passou ser incorporado à cadeia produtiva Nacional do Petróleo. Na definição de Gereffi e Fernandez-Stark (2011), as cadeias produtivas são o fluxo de informações, recursos e bens que fazem parte das atividades que integram a transformação de matérias-primas em produtos que serão destinados ao consumidor final. Basicamente, a cadeia 
EM

QUESTÃO

produtiva do petróleo compreende as seguintes etapas: extração de óleo bruto, refino, produção e distribuição de derivados para grandes distribuidoras, petroquímicas e indústrias de transformação (ALBERINI, 2011).

No Canto do Amaro são realizadas apenas as etapas de extração do óleo bruto e o seu tratamento primário. Após esses processos, toda a produção é transportada, via oleodutos, para o polo industrial de Guamaré, onde são realizadas as etapas de tratamento secundário, o estoque, a transformação e o processamento do óleo bruto nas instalações da Refinaria Potiguar Clara Camarão (RPCC) (ANP, 2017).

Em Mossoró, mesmo não ocorrendo as atividades de toda a cadeia produtiva do petróleo, a intensificação da exploração de petróleo promoveu a instalação de pequenas, médias e grandes empresas na cidade. Essa dinâmica ocasionou o recebimento de um fluxo de mão de obra, gerando uma demanda por novos serviços e por regiões habitacionais na cidade (ROCHA, 2005).

Em 2001, uma estimativa demonstrou que somente no ativo de produção de Mossoró a Petrobras contava com 54 empresas terceirizadas que empregavam cerca de 1.500 pessoas. Como consequência, o processo de acumulação de capital, criado devido ao desenvolvimento da cadeia produtiva do petróleo, foi um fator importante para a expansão da área urbana do município em virtude do surgimento de novas áreas habitacionais em locais afastados do centro da cidade (ROCHA, 2005).

Diante do exposto, a proposta deste artigo é identificar possíveis relações diretas entre as variações da produção e da instalação de poços no Canto do Amaro com indicadores econômicos do município, entre 1999 e 2015. Os dados e as análises da produção e da instalação dos poços foram comparados com os registros referentes ao recebimento de royalties, ao PIB per capita da população, ao número de pessoas ocupadas assalariadas, ao salário médio mensal e a quantidade de empresas ativas no município durante o período determinado. Desta forma, pretende-se alcançar um melhor entendimento sobre a influência das variações da produção e da instalação de poços, no Canto do Amaro, em alguns dos indicadores econômicos do município.

\section{Área de Estudo}

A área do campo de extração de petróleo do Canto do Amaro compreende partes do município de Mossoró, Areia Branca e Serra do Mel. Está distante cerca de $20 \mathrm{~km}$ do centro urbano de Mossoró e $18 \mathrm{~km}$ da cidade de Areia Branca (mapa 1).

Entre os anos analisado o campo de petróleo foi operado totalmente pela empresa Petrobras. Está localizado no nordeste da Bacia Potiguar, sobre um alto estrutural chamado de "Alto de Mossoró", que é adjacente a "linha de charneira" de Areia Branca. A área total do campo é de aproximadamente $363 \mathrm{~km}^{2}$. Desse total, cerca de $248 \mathrm{~km}^{2}$ estão inseridos no território mossoroense, o que totaliza mais de $68 \%$ da área do campo de petróleo. A produção de petróleo está associada a reservatórios existentes nas Formações Açu (idade Albiana/Cenomaniana), Alagamar (idade Aptiana) e Pendência (idade Berriasiana/Barremiana). Existem 50 zonas de produção, que variam entre as profundidades de 460m e 1300m (ANP, 2017). 
EM

QUESTÃO

V.13 N. $03 \bullet 2020$

pág. 9-32

Mapa 1 - Localização do Campo de Petróleo do Canto do Amaro.

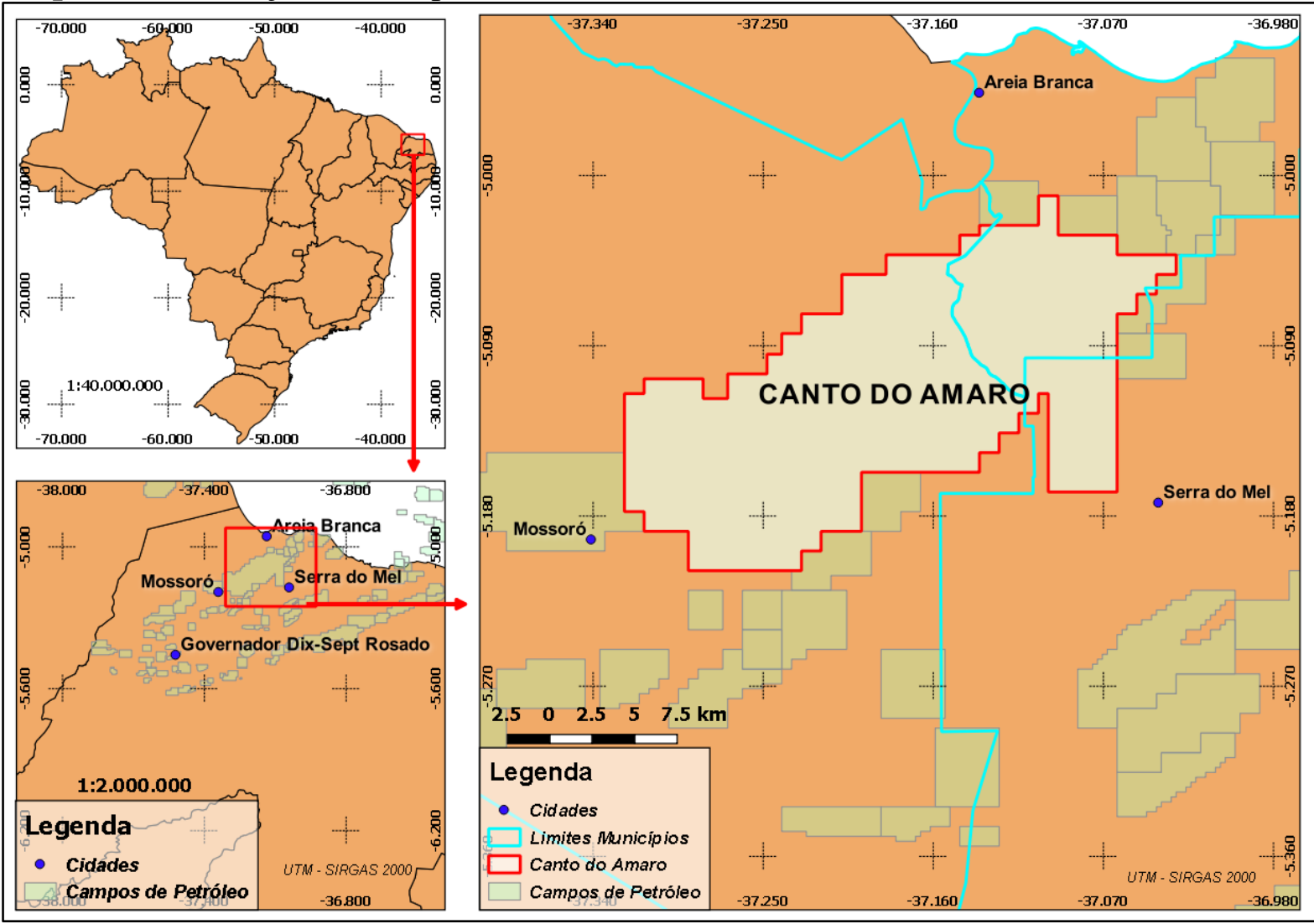

Fonte: Os autores, 2018.

\section{Períodos produtivos e a espacialização da instalação dos poços}

Períodos Produtivos

Entre os anos de 1980 e 1983, foram perfurados cinco poços no campo. Nenhum deles apresentou petróleo (mapa 2). Em 1984, não existe nenhum registro de perfuração de poço na área delimitada. No final de 1985, foi perfurado, pela operadora do campo, mais um poço, o 1-CAM-1-RN (mapa 3). Ao contrário das anteriores, nessa investida foi identificada a presença de petróleo em quantidade suficiente para ser considerado economicamente viável. 
EM

Mapa 02 - Poços perfurados entre 1980 e 1983.

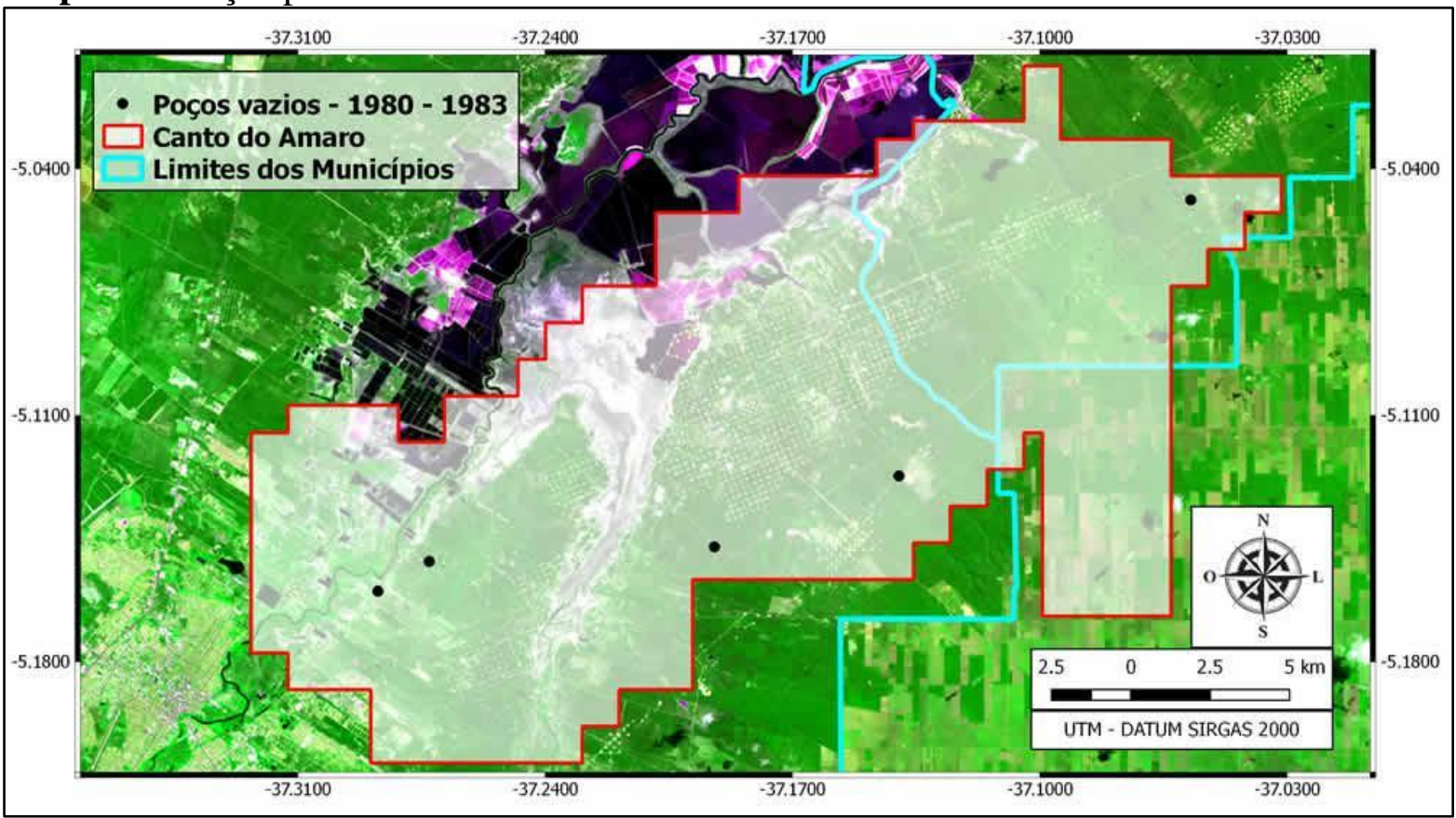

Fonte: Os autores, 2018.

Mapa 03 - Poço pioneiro 1-CAM-1-RN.

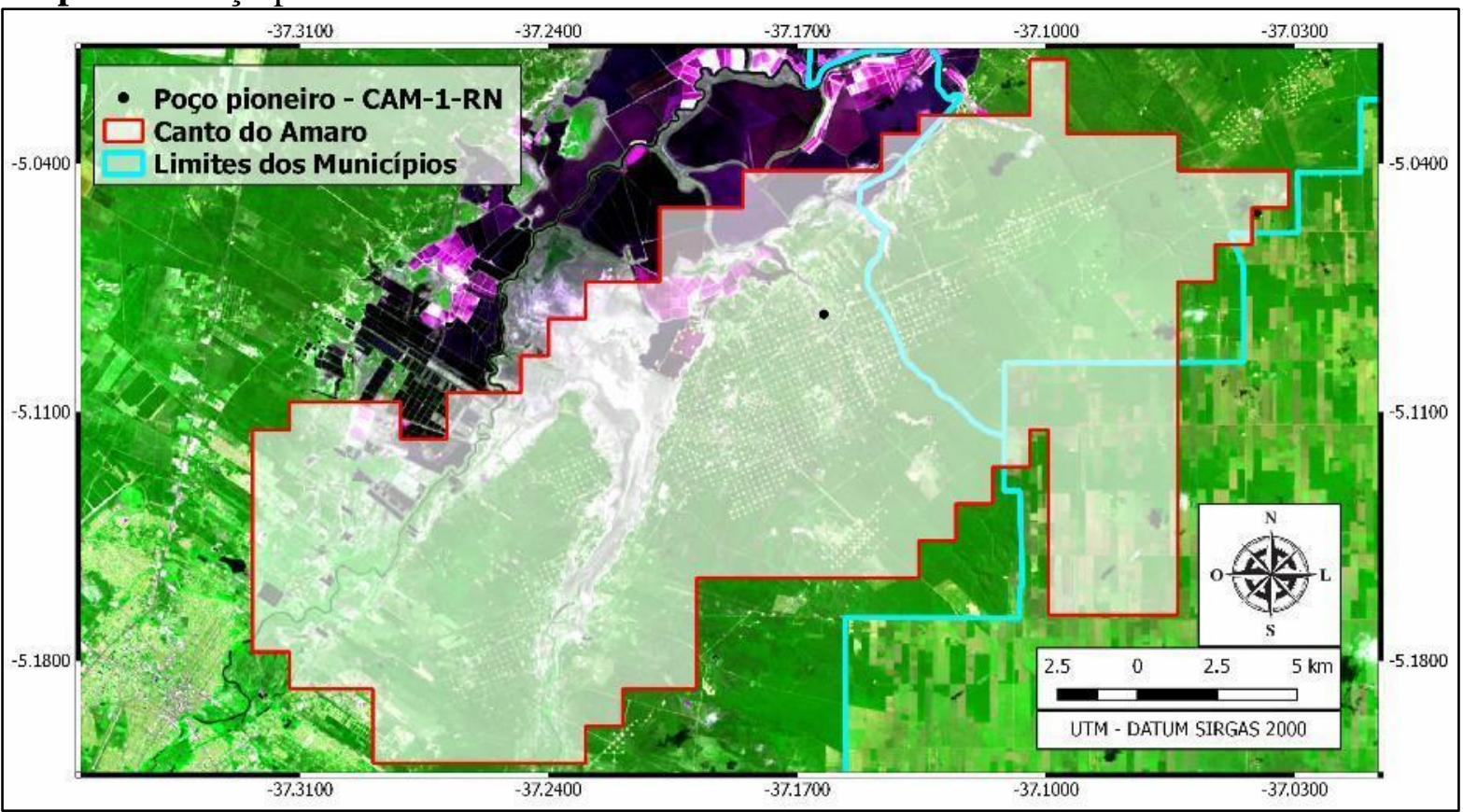

Fonte: Os autores, 2018.

Nesse contexto, em 1986, a produção do campo passou a ser registrada, anualmente pela Agência Nacional do Petróleo (ANP), conforme exposto na figura 1. O registro histórico da produção do campo permite verificar oscilações da produção, mais especificamente, para este estudo, as ocorridas entre 1986 e 2015. Nesses anos, é possível identificar seis períodos importantes na história produtiva do campo (quadro 1).

No primeiro deles entre, 1980 e 1989 ocorreu o ápice da produção. No segundo, entre 1990 e 1991, houve o início de um grande período de declínio. No terceiro recorte temporal, entre 1992 e 1995, a quantidade de barris produzidos continuou em queda. Entre 1996 e 2001, 
EM

QUESTÃO

V.13 N. $03 \bullet 2020$

pág. 9-32

o movimento negativo continuou, atingindo a menor produção registrada. No quinto período, entre 2002 e 2004, a produção do campo foi alavancada, chegando a níveis próximos aos registrados no primeiro período. No último trecho temporal delimitado, entre 2005 e 2015, a produção voltou a cair, chegando a um número próximo ao registrado no pior período produtivo do campo.

Figura 1 - Variação da produção de petróleo do Canto do Amaro entre 1986 e 2015.

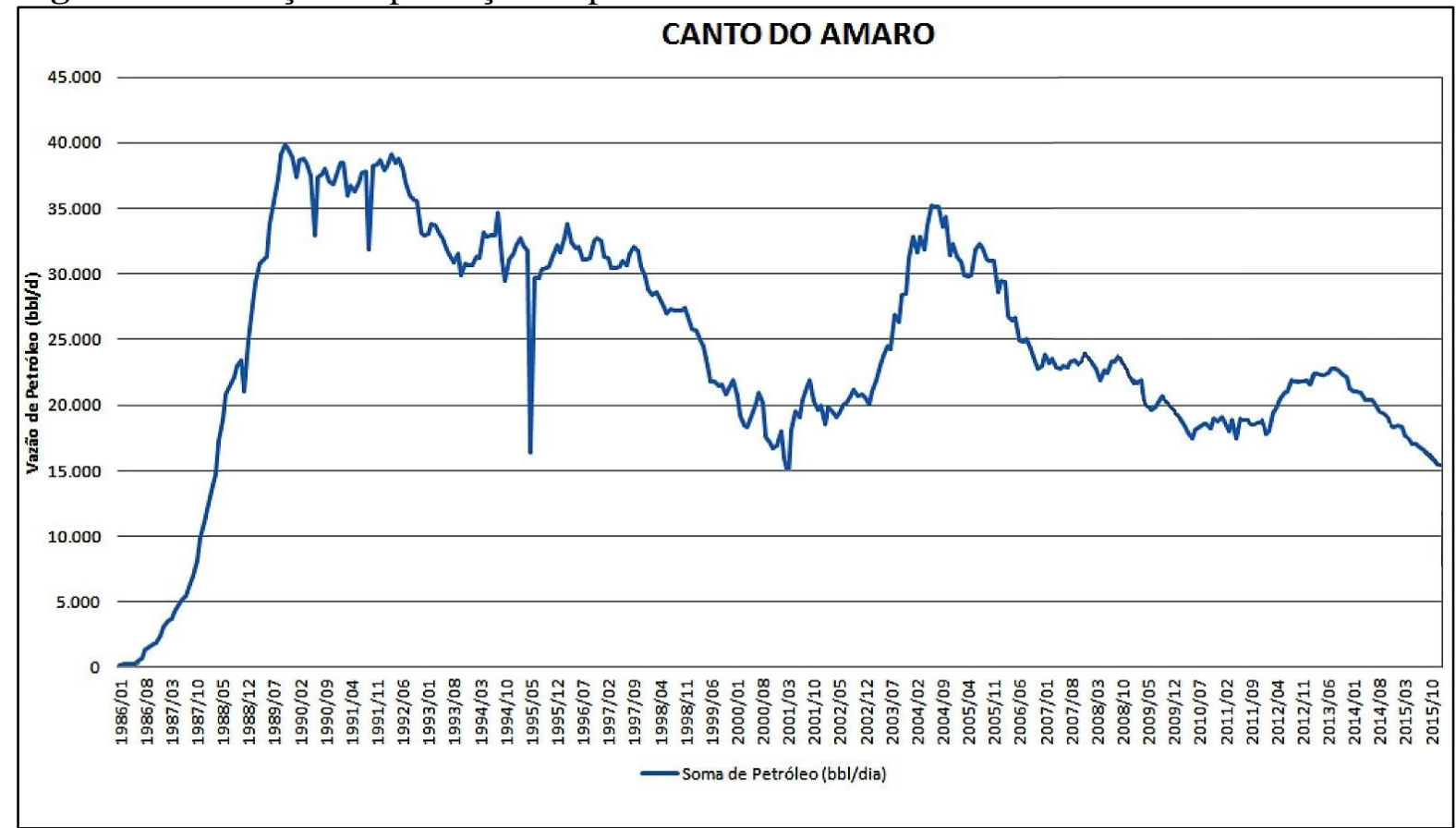

Fonte: Adaptado de ANP, 2017.

Quadro 1 - Períodos de produção do Canto do Amaro de 1986 a 2015.

\begin{tabular}{|c|c|c|c|}
\hline PERÍODOS & $\begin{array}{l}\text { ENTRE OS } \\
\text { ANOS }\end{array}$ & $\begin{array}{l}\text { OSCILAÇÃO EM RELAÇÃO } \\
\text { AO PERÍODO ANTERIOR }\end{array}$ & $\begin{array}{l}\text { CONSIDERAÇÕES SOBRE OS } \\
\text { PERÍODO }\end{array}$ \\
\hline 1 & 1980 e 1989 & Positiva & $\begin{array}{l}\text { Em } 1986 \text { houve o ápice produtivo do campo, } \\
\text { alcançando } 40 \mathrm{mil} \mathrm{bbl} / \mathrm{d} \text {. }\end{array}$ \\
\hline 2 & 1990 e 1991 & Negativa & $\begin{array}{l}\text { Primeira de três reduções consideráveis na } \\
\text { produção. A quantidade de barris produzidos } \\
\text { caiu para } 32 \mathrm{mil} \text { bbl/d. }\end{array}$ \\
\hline 3 & 1992 e 1995 & Negativa & $\begin{array}{l}\text { Segunda queda da produção. Em } 1995 \\
\text { reduziu para cerca de } 16 \mathrm{mil} \mathrm{bbl} / \mathrm{d}\end{array}$ \\
\hline 4 & 1996 e 2001 & Negativa & $\begin{array}{l}\text { Última fase do declínio produtivo. Em } 2001 \text {, } \\
\text { a produção caiu para menos de } 15 \mathrm{mil} b \mathrm{bl} / \mathrm{d} \text {. }\end{array}$ \\
\hline 5 & 2002 e 2004 & Positiva & $\begin{array}{l}\text { Elevação do patamar produtivo a níveis } \\
\text { semelhantes aos primeiros anos de } \\
\text { exploração. Em } 2004 \text { a produção alcançou } \\
\text { cerca de } 35 \mathrm{mil} \mathrm{bbl} / \mathrm{d} \mathrm{em} 2004 \text {. }\end{array}$ \\
\hline 6 & 2005 e 2015 & Negativa & $\begin{array}{l}\text { Queda produtiva atingindo, em } 2015 \text {, uma } \\
\text { produção de cerca de } 15,2 \mathrm{bbl} / \mathrm{d} \text {, a segunda } \\
\text { menor da série histórica. }\end{array}$ \\
\hline
\end{tabular}

Fonte: Os autores, 2018. 
EM

A partir da delimitação temporal produtiva em períodos, o conjunto das informações da produção de petróleo foi a base para a execução das análises entre as variáveis (perfuração de poços e indicadores econômicos) que foram comparadas. Cada verificação foi realizada considerando a oscilação positiva ou negativa da evolução dos períodos.

Espacialização da instalação dos poços no campo

Entre 1980 e 2015 foram instalados 1.873 poços no Canto do Amaro (quadro 2). A instalação das estruturas produtivas foi pulverizada em todo o campo de petróleo, com mais intensidade no centro do seu território (mapa 4).

Quadro 2 - Períodos de perfuração e instalação de poços no Canto do Amaro de 1986 a 2015.

\begin{tabular}{|c|c|c|c|}
\hline PERÍODOS & ENTRE OS ANOS & $\begin{array}{c}\text { OSCILAÇÃO EM RELAÇÃO AO } \\
\text { PERÍODO ANTERIOR }\end{array}$ & $\begin{array}{c}\text { NÚMERO DE POÇOS } \\
\text { INSTALADO NO PERÍODO }\end{array}$ \\
\hline 1 & 1980 e 1989 & Positiva & 572 \\
\hline 2 & 1990 e 1991 & Negativa & 199 \\
\hline 3 & 1992 e 1995 & Negativa & 219 \\
\hline 4 & 1996 e 2001 & Positiva & 94 \\
\hline 5 & 2002 e 2004 & Negativa & 566 \\
\hline 6 & 2005 e 2015 & Positiva & \\
\hline
\end{tabular}

Fonte: Dados ANP, 2017.

Mapa 4 - Poços instalados no Canto do Amaro entre os anos de 1980 e 2015.

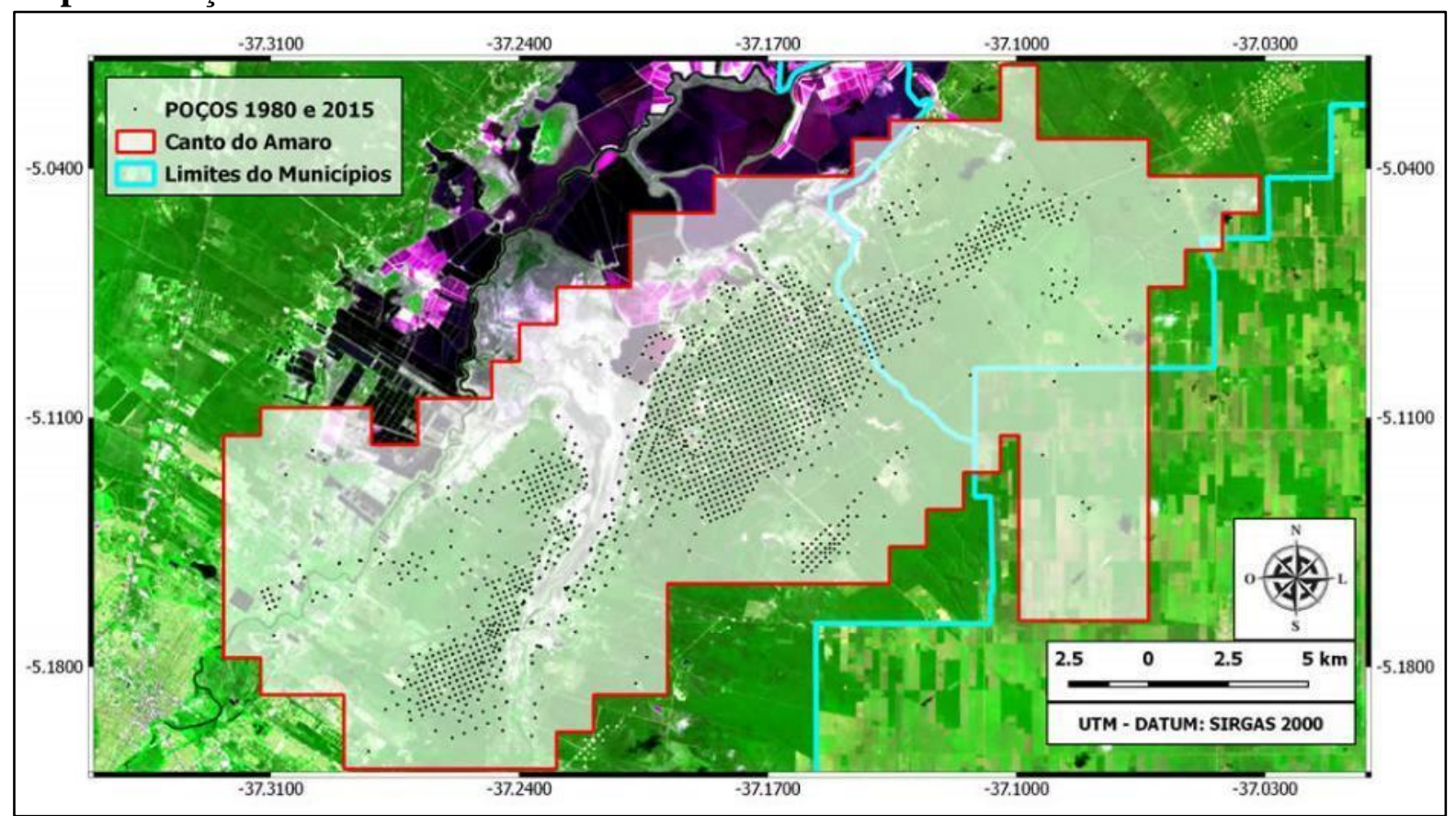

Fonte: Os autores, 2018.

A espacialização dos locais de implantação dos poços, entre os anos de 1980 e 1989, demonstra que houve uma exploração mais acentuada do centro da área do campo e secundariamente no sudoeste do seu território (mapa 5). No segundo período, inicia-se a instalação de poços na porção nordeste (mapa 6). No terceiro recorte, dos 187 poços instalados, 116 foram direcionadas para a porção central do Canto do Amaro (mapa 7). No 
EM

QUESTÃO

quarto período, a maioria dos poços foram implementados entre o centro e o sudoeste do território da área delimitada (mapa 8).

Mapa 5 - Instalação de 572 poços no Canto do Amaro entre os anos de 1980 e 1989.

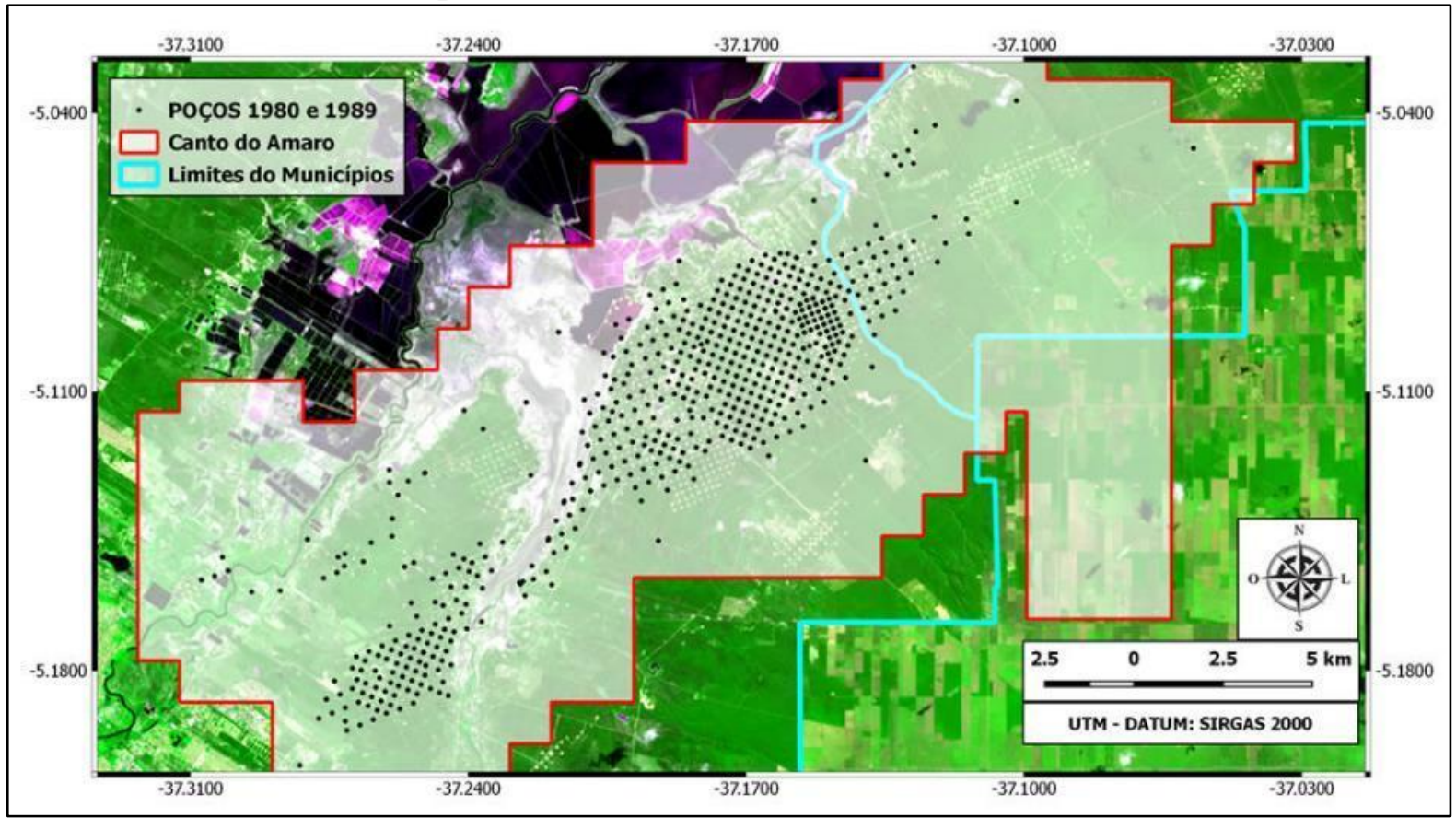

Fonte: Os autores, 2018.

Mapa 6 - Instalação de 199 poços no Canto do Amaro entre os anos de 1990 e 1991.

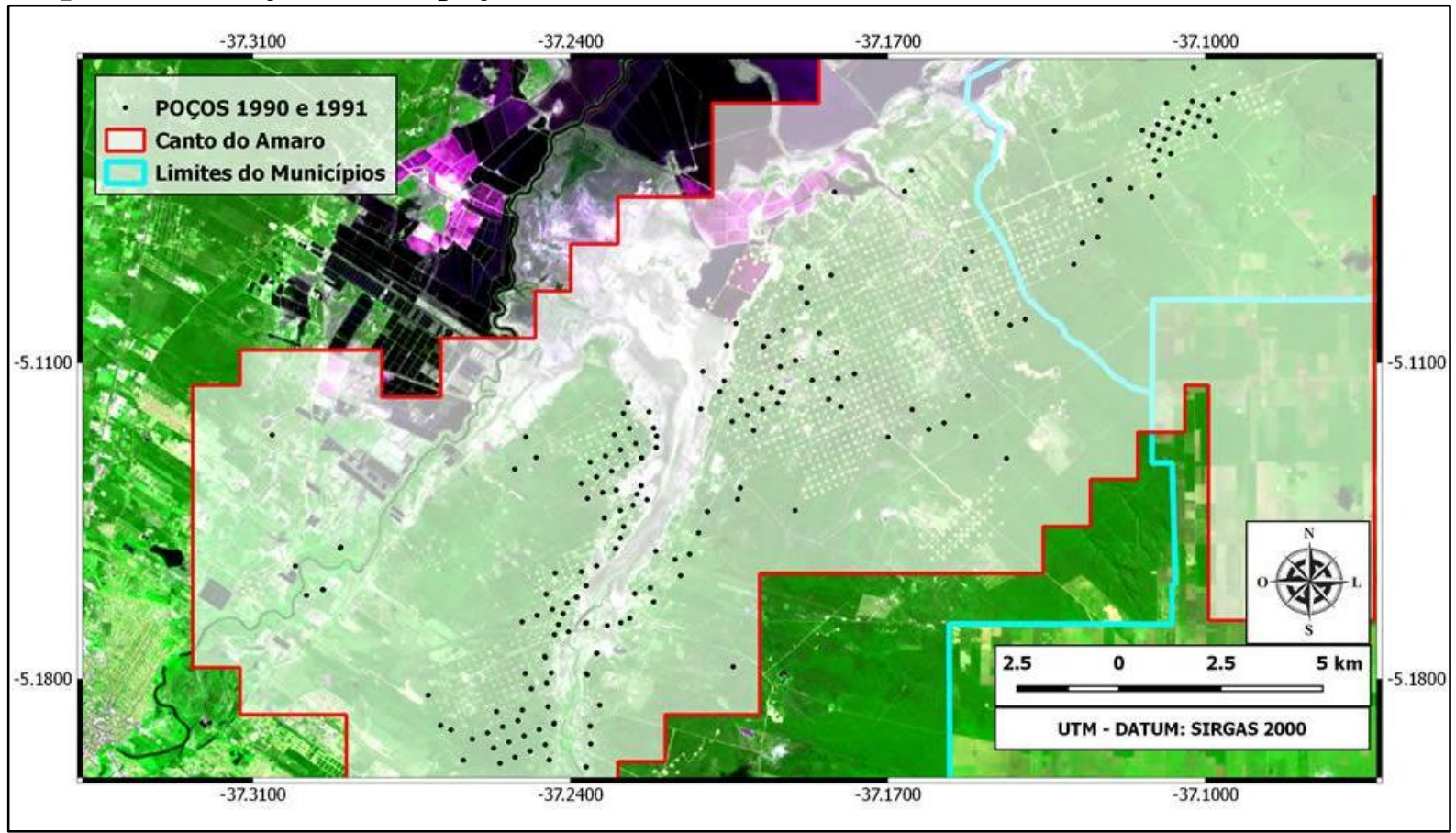

Fonte: Os autores, 2018. 
EM

QUESTÃO

V.13 N. $03 \bullet 2020$

pág. 9-32

Mapa 7 - Instalação de 187 poços no Canto do Amaro entre os anos de 1992 e 1995.

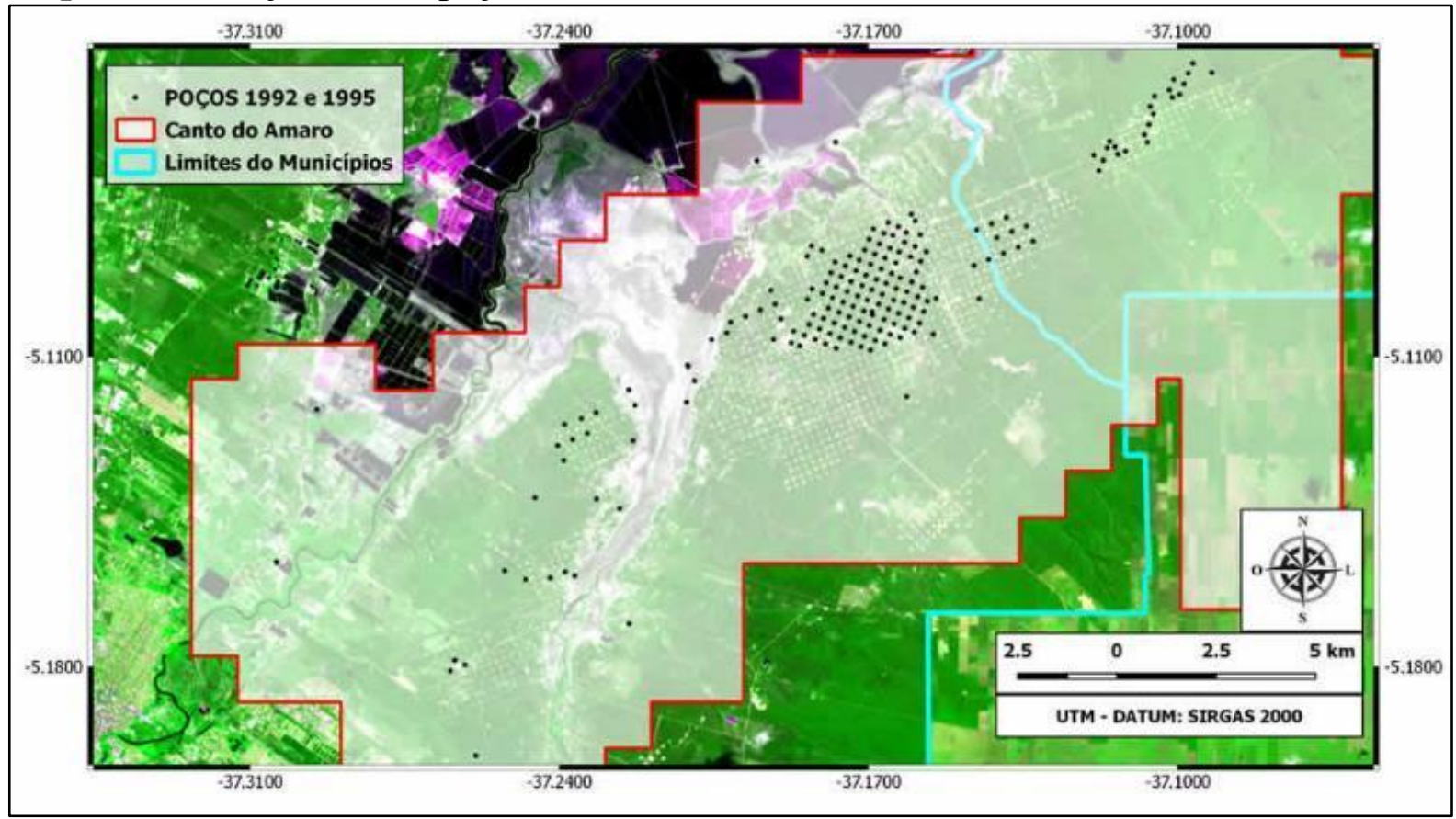

Fonte: Os autores, 2018.

Mapa 8 - Instalação de 219 poços no Canto do Amaro entre os anos de 1996 e 2001.

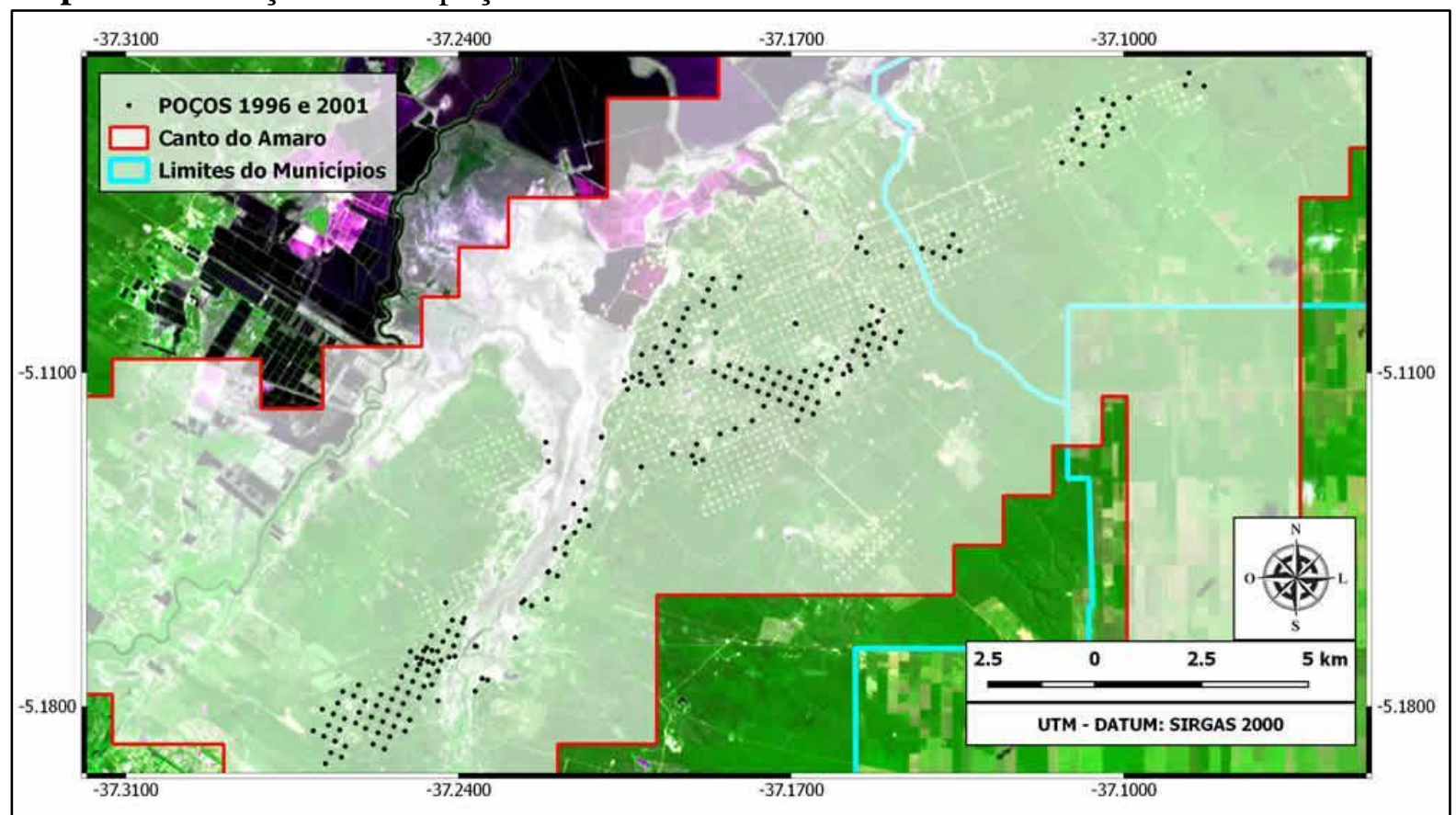

Fonte: Os autores, 2018.

No quinto, foram adicionados à estrutura produtiva do campo, somente 94 poços, principalmente na sua área central (mapa 9). 
EM

QUESTÃO

V.13 N. $03 \bullet 2020$

pág. 9-32

Mapa 9 - Instalação de 94 poços no Canto do Amaro entre os anos de 2002 a 2004.

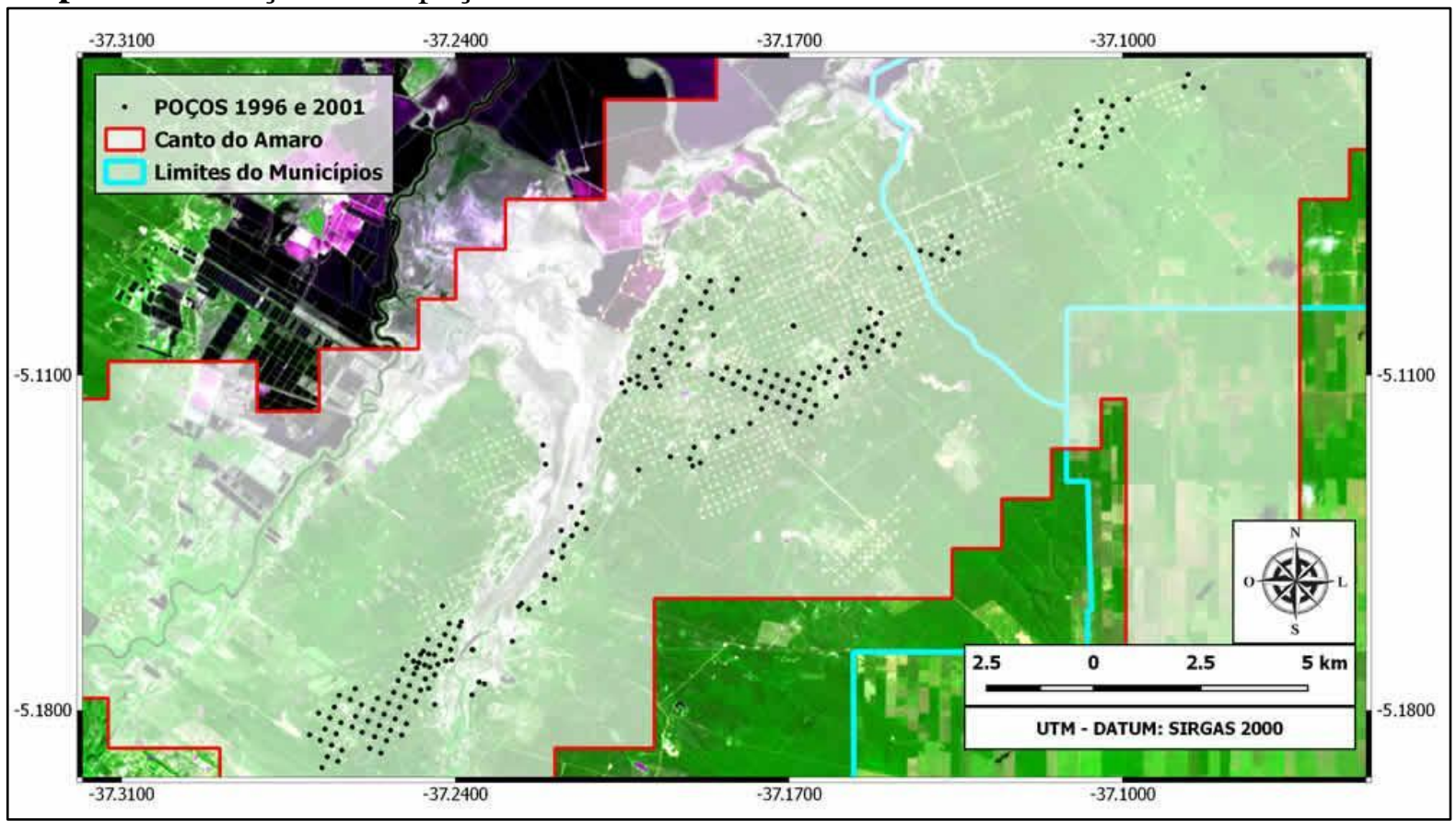

Fonte: Os autores, 2018.

No último recorte, entre os anos 2005 e 2015, houve a instalação de 566 poços, pulverizados por todas as áreas do Canto do Amaro, mas, somente na área central do campo, 317 novas estruturas de extração de petróleo foram montadas (mapa 10). Do total de poços instalados, até 2015, 1.308 já tinham produzido ou estavam produzindo petróleo com viabilidade econômica (mapa 11).

Mapa 10 - Instalação de 566 poços no Canto do Amaro entre os anos de 2005 a 2015.

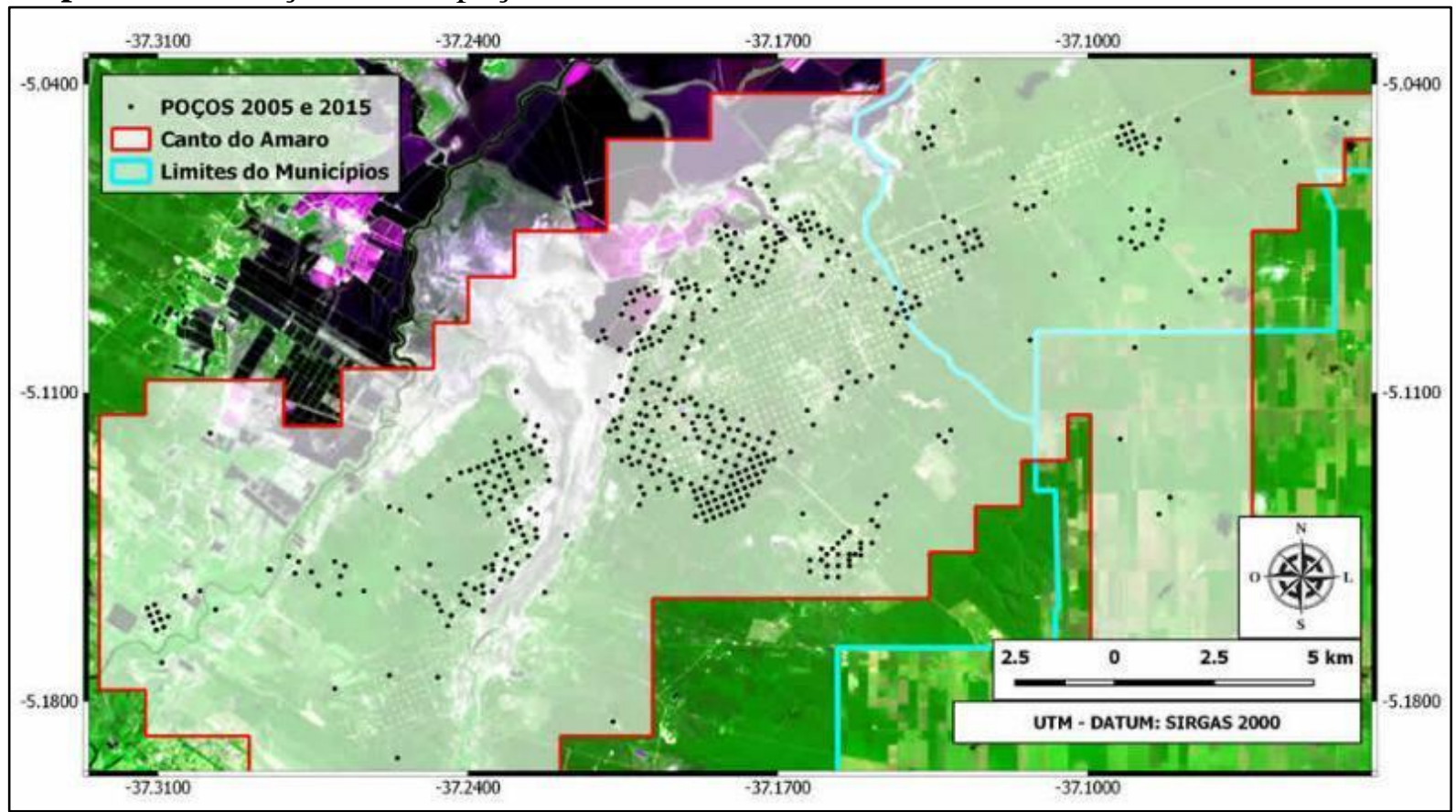

Fonte: Os autores, 2018. 
EM

A representação gráfica da área do campo de petróleo e a espacialização da instalação dos poços no campo foi realizada com o Software QGIS 2.8.15. As escalas utilizadas nos mapas apresentam diferenças devido a variação na abrangência dos locais de instalação de poços na área delimitada.

Para a criação das camadas shapefiles foram utilizados dados da ANP. A camada raster, que serve de background dos shapefiles, é formada por uma imagem do satélite LANDSAT-8, captada pelos sensores do equipamento em junho de 2017. Além disso, foram utilizados shapefiles disponibilizados pelo Instituto Brasileiro de Geografia e Estatística (IBGE). Essas camadas retratam os limites dos municípios de Mossoró, Areia Branca e Serra do Mel.

Mapa 11 - Poços que produziram ou produzem petróleo comercialmente.

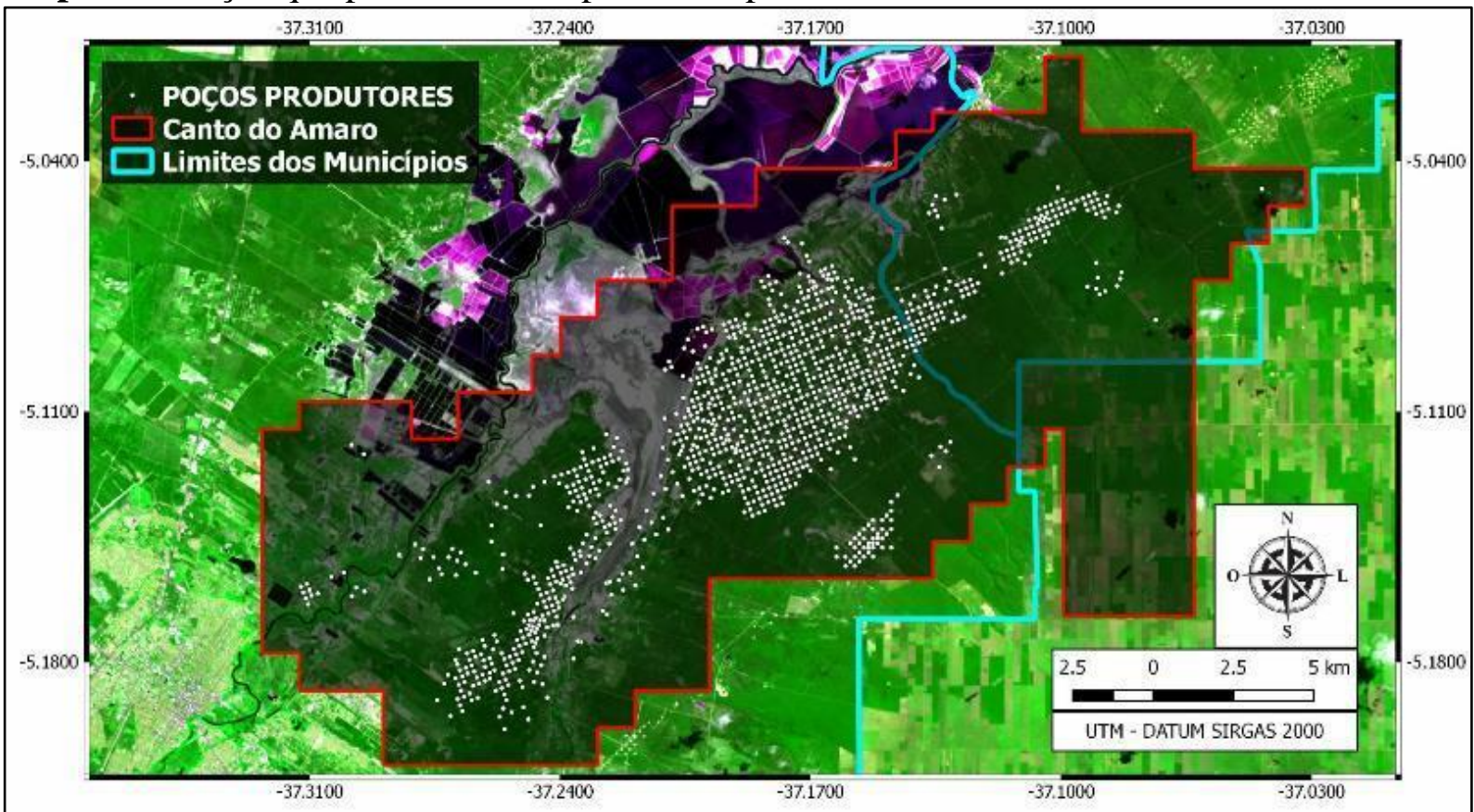

Fonte: Os autores, 2018.

\section{A variação na produção do campo e a instalação de poços}

A partir da divisão temporal da história produtiva do campo, determinada no quadro 1, foram realizadas comparações dos períodos, considerando oscilações positivas ou negativas, entre as seções temporais. $\mathrm{O}$ quadro 3 demonstra a variação existente entre a produção média anual do campo (gráfico 1) e a instalação de poços no seu território (gráfico 2).

Quadro 3 - Comparação da produção e da instalação de poços no Canto do Amaro.

\begin{tabular}{|c|c|c|c|c|}
\hline $\begin{array}{l}\mathbf{P} \\
\mathbf{E}\end{array}$ & & PRODUÇÃO & INSTALAÇÃO & \\
\hline $\begin{array}{l}\text { R } \\
\text { Í } \\
\text { O } \\
\text { D } \\
\text { O } \\
\text { S }\end{array}$ & $\begin{array}{c}\text { ENTRE } \\
\text { OS } \\
\text { ANOS }\end{array}$ & $\begin{array}{c}\text { OSCILAÇÃO } \\
\text { EM } \\
\text { RELAÇÃO } \\
\text { AO } \\
\text { PERÍODO } \\
\text { ANTERIOR }\end{array}$ & $\begin{array}{c}\text { OSCILAÇÃO } \\
\text { EM } \\
\text { RELAÇÃO } \\
\text { AO } \\
\text { PERÍODO } \\
\text { ANTERIOR }\end{array}$ & CONSIDERAÇÕES SOBRE A COMPARAÇÃO \\
\hline 1 & 1980 e 1989 & Positiva & Positiva & $\begin{array}{l}\text { A instalação de uma grande quantidade de poços (565) } \\
\text { permitiu que o campo alcançasse seu ápice produtivo. }\end{array}$ \\
\hline
\end{tabular}


EM

QUESTÃO

V.13 N. 03 \2020

pág. 9-32

\begin{tabular}{|c|c|c|c|c|}
\hline 2 & 1990 e 1991 & Negativa & Negativa & $\begin{array}{l}\text { Houve queda no ritmo de poços perfurados, mas a } \\
\text { produção manteve-se estável em um nível abaixo do } \\
\text { máximo alcançado. }\end{array}$ \\
\hline 3 & 1992 e 1995 & Negativa & Negativa & $\begin{array}{l}\text { As ações de instalação de poços recuaram, ocasionando a } \\
\text { primeira grande queda da produção, atingida no ano de } \\
1995 \text {. }\end{array}$ \\
\hline 4 & 1996 e 2001 & Negativa & Positiva & $\begin{array}{l}\text { Em 1996, a produção voltou a crescer, alcançando } 32,25 \\
\text { bbl/dia. Em } 1996 \text { foram perfurados mais } 17 \text { poços. A } \\
\text { partir de 1997, até } 2001 \text {, ocorreu uma diminuição } \\
\text { gradativa na produção, mesmo após a instalação de } 202 \\
\text { poços na área. Nesse período, a menor produção } \\
\text { registrada foi de } 18,2 \text { mil bbl/dia, em } 2001 \text {. }\end{array}$ \\
\hline 5 & 2002 e 2004 & Positiva & Negativa & $\begin{array}{l}\text { Entre } 2002 \text { e } 2004 \text {, ocorreu um aumento expressivo na } \\
\text { produção de petróleo, mesmo com o número de novas } \\
\text { instalações produtivas se mantendo estável. Em } 2004 \text {, a } \\
\text { produção de petróleo alcançou o seu segundo maior } \\
\text { índice, chegando a } 33,6 \text { bbl/dia. }\end{array}$ \\
\hline 6 & 2005 e 2015 & Negativa & Positiva & $\begin{array}{l}\text { A partir de } 2005 \text {, até o ano de } 2010 \text {, a curva de produção } \\
\text { do campo voltou a seguir o caminho de baixa, mesmo } \\
\text { ocorrendo a introdução de } 456 \text { poços. Em 2010, a } \\
\text { produção atingiu } 18,47 \text { mil bbl/dia, um pouco acima do } \\
\text { menor nível produtivo já registrado no campo. Entre } \\
2011 \text { e } 2013 \text {, houve um leve aumento produtivo, } \\
\text { chegando a faixa de } 22,27 \text { mil bbl/dia. Nesses três anos } \\
\text { foram perfurados } 81 \text { poços. Em } 2014 \text {, apenas } 7 \text { poços } \\
\text { foram implementados e em } 2015 \text { somente } 22 \text {. Nesse } \\
\text { último ano, foi registrada a menor produção da série, } \\
\text { desde de } 1988 \text {, após a instalação dos } 1837 \text { poços do } \\
\text { campo. Em } 2015 \text { a produção foi de } 16,92 \text { mil bbl/dia. }\end{array}$ \\
\hline
\end{tabular}

Fonte: Os autores, 2018.

Gráfico 1 - Média anual da produção do Canto do Amaro de 1986 a 2015.

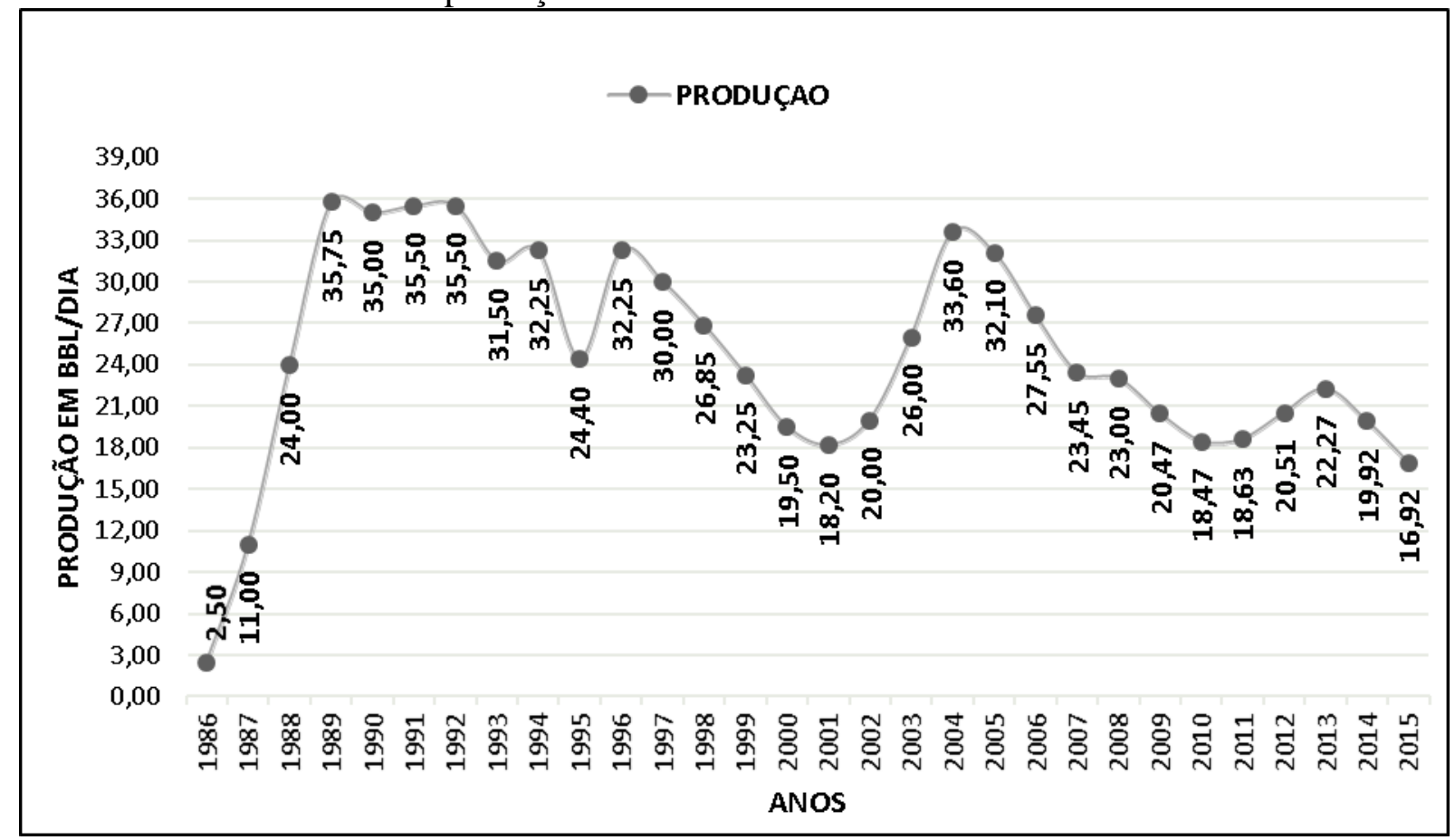

Fonte: Os autores, 2018. 
EM

Gráfico 2 - Poços perfurados no Canto do Amaro de 1986 a 2015.

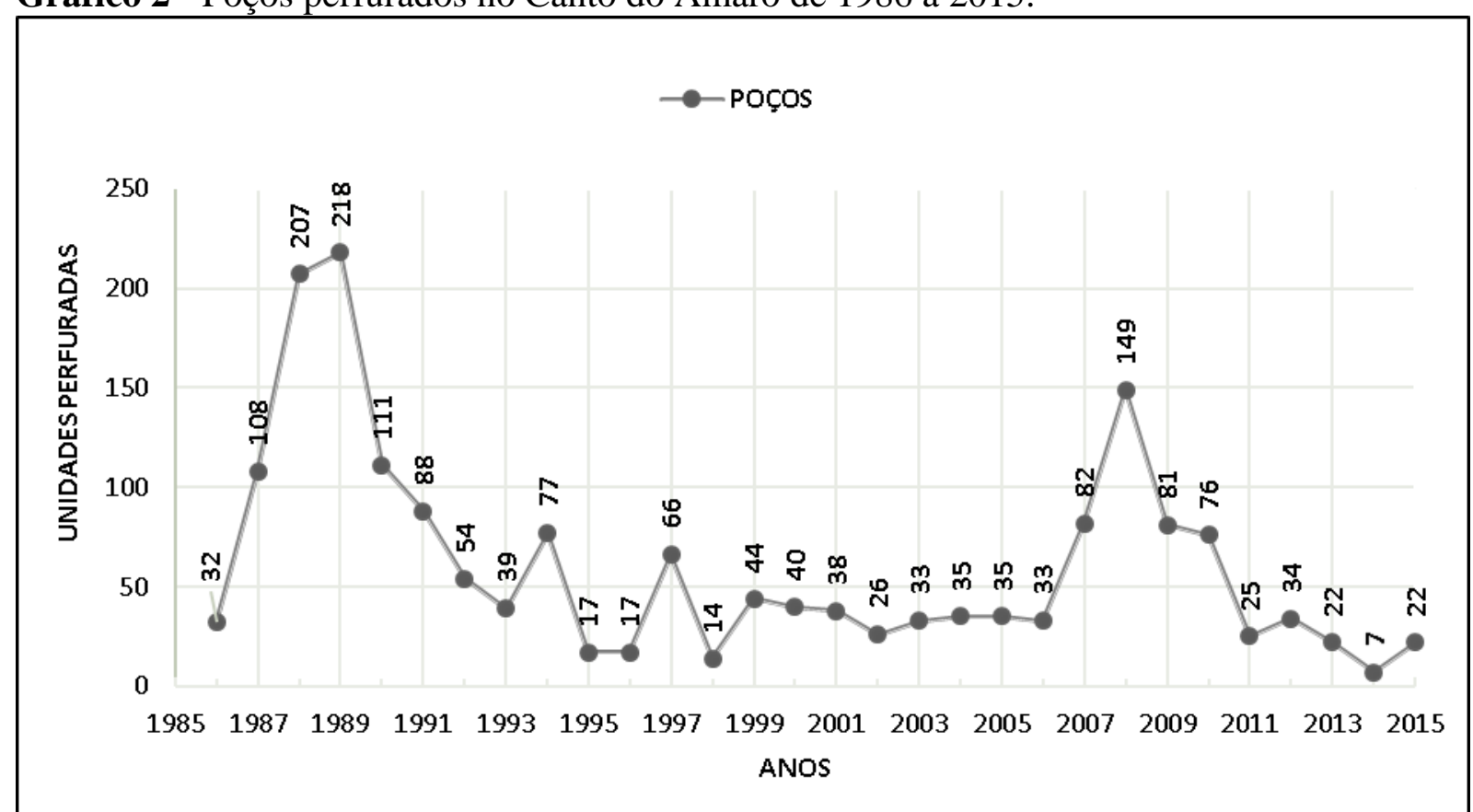

Fonte: Os autores, 2018.

A partir da comparação dos dados da produção e da instalação de novos poços é possível verificar que nos períodos 2 e 3 , do quadro 3, existe uma relação negativa semelhante entre as variáveis durante os períodos determinados. Nesses recortes é possível identificar movimentos de queda tanto da produção quanto da instalação de novos poços.

Já, nos períodos 4, 5 e 6 (quadro 3) não existem relações semelhantes. No período 4 ocorreu uma queda na produção, mesmo com o aumento na instalação de poços. No recorte 5 houve um aumento da produção, mesmo com o ritmo estável de instalação de novos poços. No período 6 é possível verificar que a produção do campo, de forma geral, oscilou sempre negativamente, mesmo com o grande incremento no número de novas instalações produtivas.

Essas assimetrias presentes na comparação do sexto período delimitado são esperadas em campos com um largo tempo de produção (BRAUNS et al., 2010). A ANP define esse tipo de local de exploração como campo maduro. Para a agência reguladora, o campo de petróleo torna-se maduro quando a sua produção histórica efetiva é maior ou igual a vinte e cinco anos (ANP, 2018).

Nos campos maduros a produção tende a diminuir com o tempo de extração devido a diminuição da pressão no interior do reservatório da formação rochosa que contêm hidrocarbonetos. Nessa situação é necessário injetar água no reservatório com o objetivo de aumentar a pressão interna da formação e retirar o restante do mineral (BRAUNS et al., 2010)

\section{A influência da produção e instalação de poços no Canto do Amaro nos indicadores econômicos}

Os dados dos indicadores econômicos que foram analisados neste trabalho estão disponíveis a partir do ano de 1999. Todos eles apresentam sequências até 2015.

Os royalties e o PIB Per Capita do município apresentam registros a partir do ano de 1999. Já, as informações referentes as pessoas ocupadas, salário médio mensal e empresas atuantes no município, tiveram suas séries históricas registradas pelo IBGE a partir 2006. 
EM

Devido a essa lacuna de dados, os royalties e o PIB per capta foram comparados com a produção e a instalação de poços com o auxílio de quadros específicos, considerando apenas os três últimos períodos determinado no quadro 01. Para os outros indicadores, o processo de verificação foi realizado por meio da análise de figuras que contemplam gráficos da produção, da instalação de poços e do indicador econômico.

Os Royalties

A ANP, em seu sítio na web, disponibiliza os valores dos royalties pagos aos municípios produtores de petróleo do país (gráfico 3).

Gráfico 3 - Royalties pagos ao município de Mossoró/RN entre 1999 e 2015.

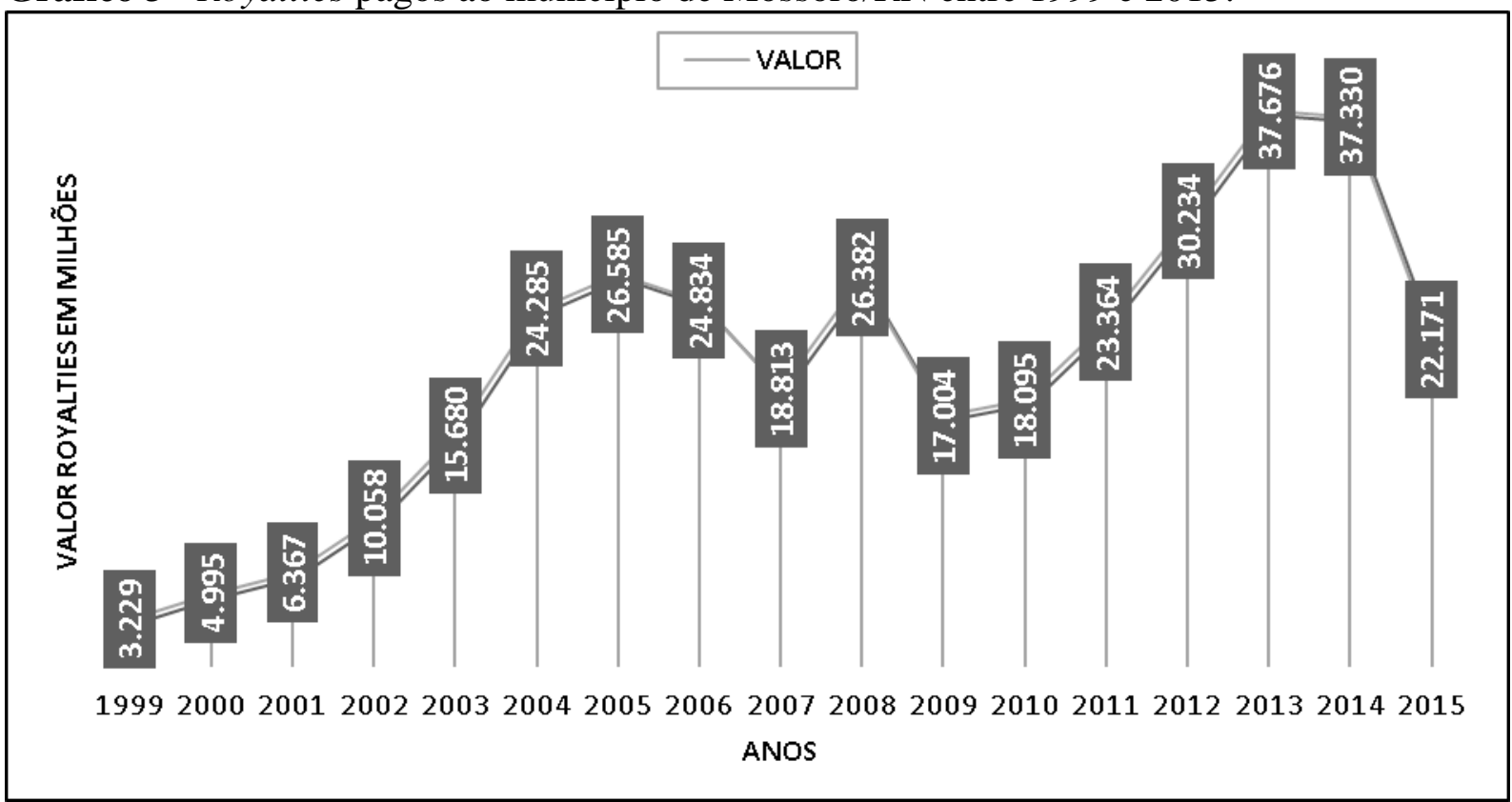

Fonte: Os autores, 2018.

No gráfico acima é possível verificar, com algumas exceções, um acréscimo crescente no valor dos royalties pagos ao município de Mossoró. O cálculo desses valores é realizado por um órgão interno da ANP considerando fatores como a produtividade dos poços, as instalações produtivas e as zonas de influência da atividade em cada município (ANP, 2010). Com essas informações foi possível criar um quadro comparativo entre a produção, a instalação de poços e os valores dos royalties (quadro 4).

Quadro 4 - Comparação da produção, instalação de poços e os valores de royalties pagos ao município.

\begin{tabular}{|c|c|c|c|c|c|}
\hline $\mathbf{P}$ & & Produção & Instalação & Royalties & \\
\hline $\begin{array}{l}\text { R } \\
\text { Í } \\
\text { O } \\
\text { D } \\
\text { O } \\
\text { S }\end{array}$ & $\begin{array}{c}\text { ENTRE } \\
\text { OS } \\
\text { ANOS }\end{array}$ & $\begin{array}{c}\text { OSCILAÇÃO } \\
\text { EM } \\
\text { RELAÇÃO } \\
\text { AO } \\
\text { PERÍODO } \\
\text { ANTERIOR }\end{array}$ & $\begin{array}{c}\text { OSCILAÇÃO } \\
\text { EM } \\
\text { RELAÇÃO } \\
\text { AO } \\
\text { PERÍODO } \\
\text { ANTERIOR }\end{array}$ & $\begin{array}{c}\text { OSCILAÇÃO } \\
\text { EM } \\
\text { RELAÇÃo } \\
\text { AO } \\
\text { PERÍODO } \\
\text { ANTERIOR }\end{array}$ & CONSIDERAÇÕES \\
\hline 1 & 1980 e 1989 & Positiva & Positiva & Sem dados & - \\
\hline 2 & 1990 e 1991 & Negativa & Negativa & Sem dados & - \\
\hline 3 & 1992 e 1995 & Negativa & Negativa & Sem dados & \\
\hline
\end{tabular}


EM

\begin{tabular}{|c|c|c|c|c|c|}
\hline 4 & 1996 e 2001 & Negativa & Positiva & Positiva & $\begin{array}{l}\text { Até o fim de } 1999 \text {, no Canto do } \\
\text { Amaro, já existiam } 1099 \text { poços } \\
\text { perfurados. Nesse ano, foi } \\
\text { repassado ao município um valor de } \\
\mathrm{R} \$ 3,229 \text { milhões. Entre os anos de } \\
1996 \text { e 2001, a produção de } \\
\text { petróleo estava em declínio, } \\
\text { chegando ao um dos níveis mais } \\
\text { baixos já registrados. Mas, entre } \\
1999 \text { e } 2001 \text { o valor dos royalties } \\
\text { pagos ao município aumentou. }\end{array}$ \\
\hline 5 & 2002 e 2004 & Positiva & Negativa & Positiva & $\begin{array}{l}\text { Entre os anos de } 2002 \text { a } 2004, \\
\text { mesmo com a instalação de poços } \\
\text { no campo mantendo-se estável, a } \\
\text { produtividade passou de } 20 \text { mil } \\
\text { bbl/dia para } 33,6 \text { mil bbl/dia. Entre } \\
\text { esses anos verifica-se um aumento } \\
\text { brusco no valor do pagamento de } \\
\text { royalties ao município. Em } 2004, \\
\text { no ápice da produção do período, } \\
\text { valor pago foi de R } \$ 24,285 \\
\text { milhões. }\end{array}$ \\
\hline \multirow[t]{2}{*}{6} & \multirow[t]{2}{*}{2005 e 2015} & \multirow[t]{2}{*}{ Negativa } & \multirow[t]{2}{*}{ Positiva } & Positiva & $\begin{array}{l}\text { Em } 2005 \text {, mesmo com a produção } \\
\text { mais baixa, o valor pago foi } \\
\text { superior ao de 2004, chegando a um } \\
\text { total de } \mathrm{R} 26,585 \text { milhões. Nos } \\
\text { anos de } 2006 \text { e } 2007 \text { houve uma } \\
\text { queda de produção e o também do } \\
\text { valor do pagamento. Já em } 2008 \text {, } \\
\text { houve um pico na perfuração de } \\
\text { poços no campo. Nesse ano foram } \\
\text { implementados } 149 \text { novos } \\
\text { equipamentos, mas a produção não } \\
\text { teve incremento, chegando a } \\
\text { registrar um valor menor do que a } \\
\text { de } 2007 \text {. Mesmo assim houve um } \\
\text { crescimento no pagamento dos } \\
\text { royalties ao município. Entre os } \\
\text { anos de } 2009 \text { e } 2010 \text {, verifica-se um } \\
\text { aumento no ritmo da instalação de } \\
\text { poços. A produção de petróleo do } \\
\text { campo, entre } 2009 \text { e } 2015 \text { seguiu } \\
\text { em queda, até atingir o nível mais } \\
\text { baixo em } 2015 \text {, mas essa condição } \\
\text { não se reflete no valor dos royalties } \\
\text { pagos. De } 2009 \text { a } 2014 \text { o valor } \\
\text { aumentou, chegando a ser pago, em } \\
\text { 2013, R } \$ 37,676 \text { milhões }\end{array}$ \\
\hline & & & & Negativa & $\begin{array}{l}\text { Já em } 2015 \text {, o repasse do dinheiro } \\
\text { diminuiu } R \$ 15,159 \text { milhões, em } \\
\text { relação ao pico de } 2013 \text {, seguindo a } \\
\text { queda da produção e da perfuração } \\
\text { de poços no campo, que chegou ao } \\
\text { seu nível mais baixo. }\end{array}$ \\
\hline
\end{tabular}

Fonte: Os autores, 2018.

Analisando as informações presentes no quadro 4 verifica-se que, nos períodos 4 e 5 , mesmo a produção e a instalação de poços tendo oscilado positivamente e negativamente, houve um crescente no valor dos royalties pago ao município. Já, no período 6, existe uma variação positiva e negativa em relação à variação dos royalties.

Essas constatações permitem visualizar que a produção de petróleo do campo e da instalação de novos poços não são isoladamente, os formadores do valor dos royalties pago ao município. Consequentemente, essa variação dos royalties é resultado da forma como é 
EM

QUESTÃO

V.13 N. $03 \bullet 2020$

pág. 9-32

composto o cálculo do montante que será pago aos municípios produtores de petróleo. Esses valores oscilam de acordo, além da produção, com a taxa de câmbio das moedas (real e dólar) e do preço internacional do barril de petróleo (JESUS et al., 2017).

\section{PIB Per Capita}

O IBGE iniciou a publicação, em 1999, do valor do produto interno bruto dos municípios brasileiros. A metodologia para a realização do cálculo leva em conta o valor adicionado (a preço corrente) às contas regionais do Brasil, pelas atividades econômicas realizadas em cada município. Por meio desse procedimento estima-se o valor adicionado por atividades agropecuárias, indústrias e de serviços. Considerando o petróleo, a contribuição da extração do mineral para o PIB dos municípios produtores é estimada por meio das informações angariadas junto à Agência Nacional do Petróleo, que detalham a composição dos royalties pagos (IBGE, 2004).

A partir da determinação do valor do PIB é possível verificar o PIB per capita municipal, que é o valor da divisão do PIB do ano pela população residente no município no mesmo período (gráfico 4).

Gráfico 4 - PIB per capita de Mossoró/RN entre 1999 e 2015.

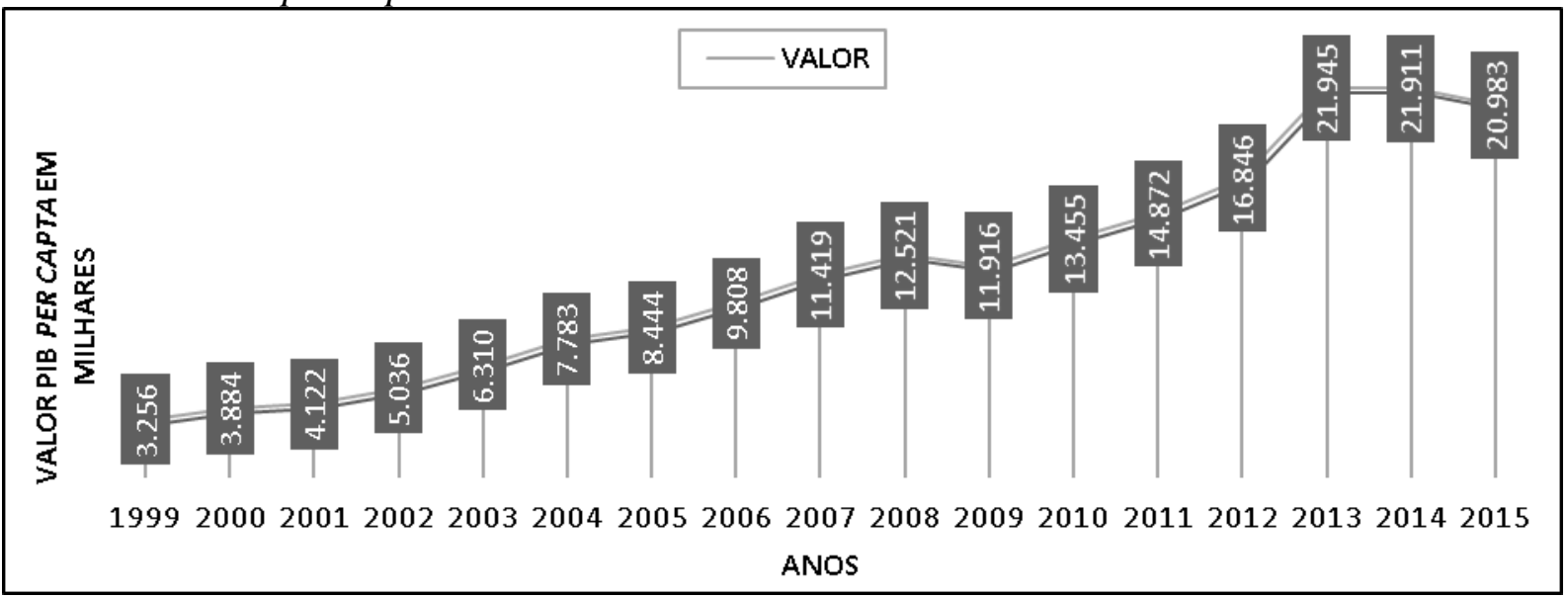

Fonte: Os autores, 2018.

Em Mossoró, esse índice manteve-se em uma alta contínua de 1999 a 2008. Em 2009 houve uma quebra nessa dinâmica, mas logo em 2010 foi retomado o crescimento. Em 2013, ocorreu um aumento significativo, do valor do PIB Per Capta em relação aos anos anteriores. O valor alcançou $R$ \$ 21.945,00, mais de $R$ \$ 8.000,00, em relação ao ano de 2012. Em 2014 e 2015, o valor recuou, mas continuou acima de $\mathrm{R} \$ 20.000,00$. Utilizando essas informações foi possível criar um quadro comparativo entre a produção, a instalação de poços e o indicador (quadro 05).

Quadro 5 - Comparação da produção, instalação de poços e do PIB Per Capta do município.

\begin{tabular}{|c|c|c|c|c|c|}
\hline $\mathbf{P}$ & & Produção & Instalação & PIB Per Capta & \\
\hline $\begin{array}{l}\text { R } \\
\text { Í } \\
\text { O } \\
\text { D } \\
\text { O } \\
\text { S }\end{array}$ & $\begin{array}{c}\text { ENTRE } \\
\text { OS } \\
\text { ANOS }\end{array}$ & $\begin{array}{c}\text { OSCILAÇÃo } \\
\text { EM } \\
\text { RELAÇÃO } \\
\text { AO } \\
\text { PERÍODO } \\
\text { ANTERIOR }\end{array}$ & $\begin{array}{c}\text { OSCILAÇÃO } \\
\text { EM } \\
\text { RELAÇÃO } \\
\text { AO } \\
\text { PERÍODO } \\
\text { ANTERIOR }\end{array}$ & $\begin{array}{c}\text { OSCILAÇ̃̃o } \\
\text { EM } \\
\text { RELAÇÃo } \\
\text { AO } \\
\text { PERÍODO } \\
\text { ANTERIOR }\end{array}$ & CONSIDERAÇÕES \\
\hline 1 & 1980 e 1989 & Positiva & Positiva & Sem dados & \\
\hline
\end{tabular}


EM

\begin{tabular}{|c|c|c|c|c|c|}
\hline 2 & 1990 e 1991 & Negativa & Negativa & Sem dados & - \\
\hline 3 & 1992 e 1995 & Negativa & Negativa & Sem dados & - \\
\hline 4 & 1996 e 2001 & Negativa & Positiva & Positiva & $\begin{array}{l}\text { Houve uma diminuição gradativa } \\
\text { na produção, ocorrendo em } \\
\text { paralelo com um acréscimo na } \\
\text { instalação de poços. Entre os anos } \\
\text { de } 1999 \text { a } 2001 \text { o valor do PIB } \\
\text { per capita cresceu. }\end{array}$ \\
\hline 5 & 2002 e 2004 & Positiva & Negativa & Positiva & $\begin{array}{l}\text { O aumento expressivo na } \\
\text { produção de petróleo, entre } 2002 \\
\text { e } 2004, \text { mesmo com uma } \\
\text { diminuição no ritmo da instalação } \\
\text { de poços, vai de encontro com o } \\
\text { crescente valor do PIB Per Capta. } \\
\text { Ao final do período, em que a } \\
\text { produção de petróleo alcançou o } \\
\text { seu segundo maior índice, o valor } \\
\text { do PIB Per Capta já acumulava } \\
\text { uma alta de } 105 \% \text {, desde } 1999 \text {. }\end{array}$ \\
\hline 6 & 2005 e 2015 & Negativa & Positiva & Positiva & $\begin{array}{l}\begin{array}{l}\text { Durante o período o valor do } \\
\text { indicador }\end{array} \\
\text { consideravelmente, } \\
\text { ocosmondo oscilaçôes constantes } \\
\text { na produção e na instalação de } \\
\text { novos poços no campo. }\end{array}$ \\
\hline
\end{tabular}

Fonte: Os autores, 2018.

Com as informações presente no quadro 5 identifica-se que as variações não apresentam relação direta. Entre os anos analisados, as oscilações da produção e da instalação de novos poços no campo não alteraram, significativamente, o crescimento do PIB Per Capta do município.

Em relação à produção do Canto do Amaro, entre os anos de 1999 e 2008, a oscilação produtiva do campo (gráfico 1) não apresenta semelhança com a evolução do indicador do município (gráfico 4), pois entre 1999 e 2008 o aumento desse índice chegou a mais de 384\%.

Mesmo, de forma geral, não existindo verificações semelhantes nas comparações, alguns pontos podem ser destacados em relação à produção, pois demonstram a mesma dinâmica de oscilação. Um deles pode ser visualizado no ano de 2009 quando a produção do campo chegou a um baixo patamar devido a um movimento de queda, desde do ano de 2006. Nesse mesmo ano o PIB Per Capita também registrou uma sensível queda, o que descontinuou a curva de crescimento contínua do índice. Entre os anos de 2014 e 2015, após um aumento da produção em 2013, houve uma queda. Esse mesmo movimento de retração também é visível no PIB Per Capta registrado nos anos de 2013, 2014 e 2015.

Visualizando as variações da instalação de poços no Canto do Amaro e a oscilação do índice destacado, é possível identificar alguma semelhança somente entre os anos de 2014 e 2015. Nesse período a implementação de novas instalações produtivas ( 7 poços em 2014 e 22 em 2015) foi muito baixa.

Portanto, o resultado da análise comparativa das variáveis relacionadas ao campo de petróleo é que elas não apresentam influência direta no valor do PIB Per Capta do município. Essa constatação não exclui a importância das atividades da cadeia produtiva do petróleo no município. Apenas aponta que, nos períodos avaliados, a exploração e produção do mineral contribuíram, paralelamente, com outras atividades econômicas realizadas na unidade da federação. 
EM

Pessoas ocupadas, salário médio mensal e empresas atuantes

Somente a partir de 2006 o IBGE iniciou a série histórica desses indicadores. Por consequência, não foi possível comparar as informações seguindo a divisão temporal realizada no quadro 1. As comparações dos indicadores com as variáveis de produção e instalação de poços foi realizada considerando apenas o intervalo entre os anos de 2006 a 2015.

\section{Pessoas ocupadas}

O indicador "Pessoal Ocupado Assalariado" (POA) reflete o total de trabalhadores assalariados em atividade, no último dia de cada mês, ligados ou não ao processo produtivo (IBGE, 2017). Sobre Mossoró, existem dados disponíveis de 2006 a 2015. Fazendo uso das informações do indicador, juntamente com os dados da produção e da instalação de poços, foi possível montar uma figura com os gráficos das três variáveis (figura 2) para permitir a comparação entre elas.

Figura 2 - Gráficos de pessoas ocupadas, produção do campo e instalação de poços entre 2006 e 2015.

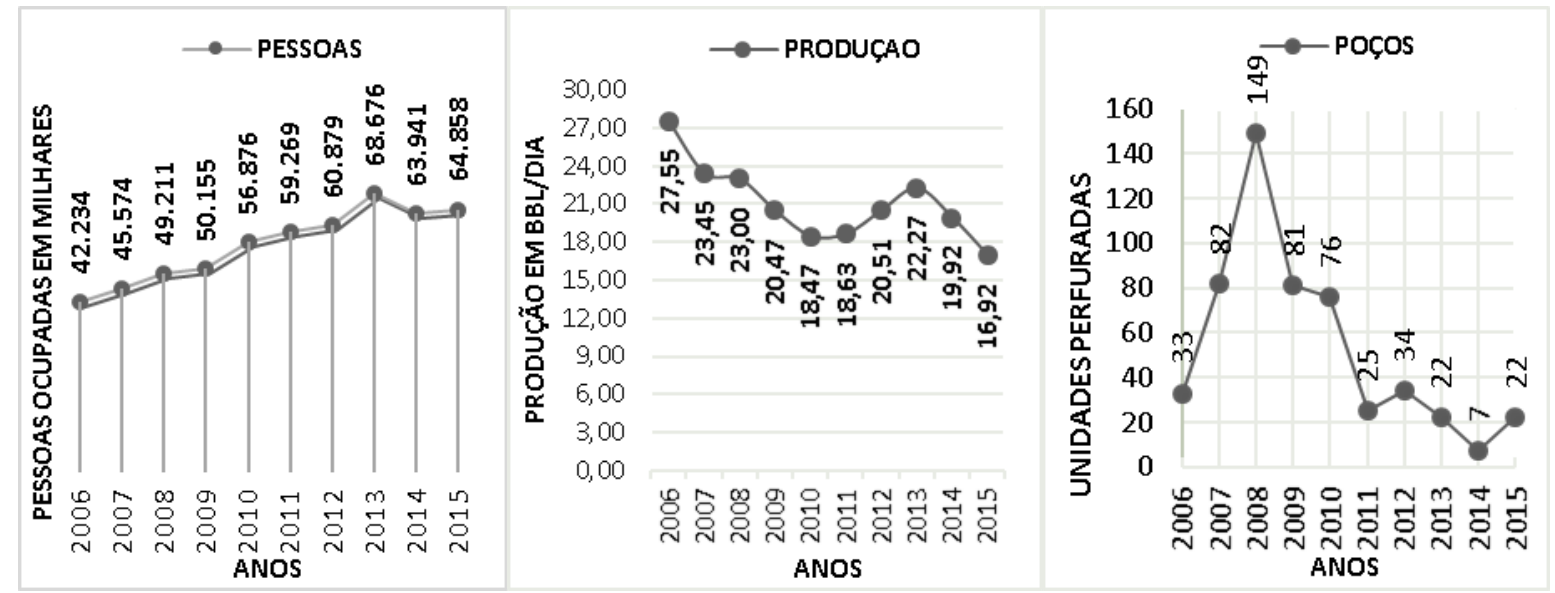

Fonte: Os autores, 2018.

Com pode ser visualizado na figura 2, até 2013 ocorreram aumentos sucessivos nos valores registrados. Já, em 2014 é possível visualizar uma queda de 4.735 pessoas ocupadas em Mossoró, em relação a 2013.

Em 2015, houve um aumento, mas não esse incremento não recuperou o valor da queda que ocorreu em 2014. Relacionando esses dados com a produção e a instalação de poços no campo, não é possível identificar reflexos das oscilações desses dois últimos fatores, entre os anos de 2006 e 2013, no número de pessoas ocupadas no município.

Já, em 2014, a queda da produção e da implementação de novos equipamentos coincide com a diminuição de mais de 4.000 pessoas no número do indicador. Em 2015, mesmo com a diminuição da produção e considerando um pequeno aumento da perfuração de poços, ocorreu um aumento de 917 no indicador POA.

Considerando que as informações sobre o indicador do IBGE apresentam dados somente a partir de 2006, não é possível determinar que a produção e a instalação de novos poços no campo possuem relação direta com a quantidade de pessoas ocupadas no município.

Diante desse contexto, é provável que a quantidade de pessoas absorvidas como mão de obra, dentro da cadeia produtiva de petróleo existente na região, não tenha uma 
EM

representatividade tão alta em relação às outras atividades econômicas realizadas no município.

É importante destacar que o percentual mais significativo de investimentos na cadeia produtiva, e consequentemente, a geração de empregos, está associada às fases de prospecção e desenvolvimento da produção. É nessa etapa que os poços produtores são perfurados e demais equipamentos são instalados para iniciar, ou incrementar a produção de uma área extratora de petróleo (PIQUET, 2010). Aplicando esse olhar sobre o Canto do Amaro, por ele ser um campo maduro na definição da ANP, a diminuição da sua produção ao longo do período determinado evidencia que a sua capacidade de influenciar diretamente nesse fator é reduzida.

\section{Salário Médio mensal}

Esse indicador é calculado a partir da razão entre o total de salários e outras remunerações pagas, no ano, a variável "pessoal assalariado médio", dividido por treze. A sua base de dados é da Relação Anual de Informações Sociais (RAIS) (IBGE, 2015). As oscilações do salário médio mensal, da produção e da instalação de poços entre os anos de 2006 e 20015 podem ser visualizadas na figura 3.

Figura 3 - Gráficos de salário médio mensal, produção do campo e instalação de poços entre 2006 e 2015.

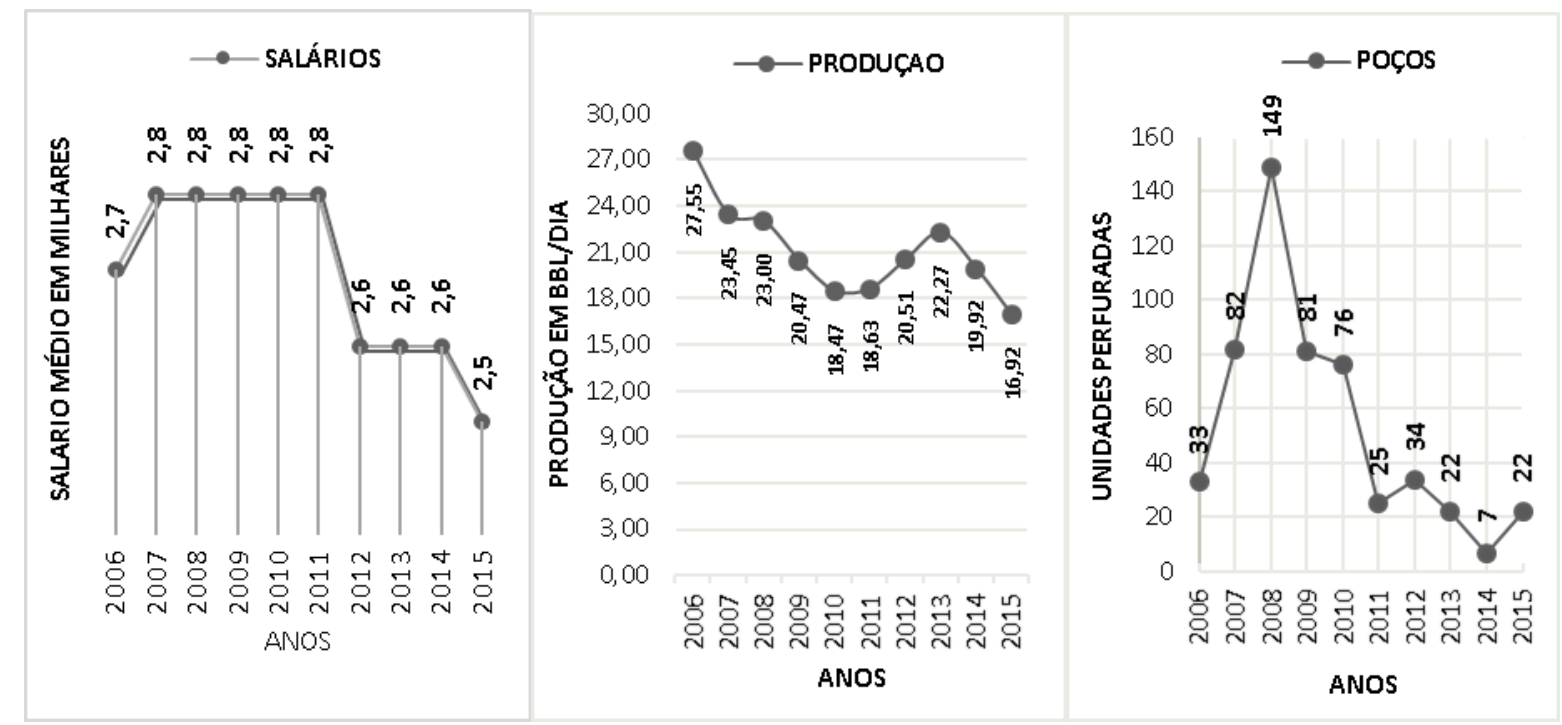

Fonte: Os autores, 2018.

As informações da figura 3 indicam que entre 2006 e 2011 o salário médio calculado em Mossoró manteve-se estável. Já, em 2012, 2013 e 2014, o valor caiu para 2,6. Em 2015 o valor voltou a cair, atingindo 2,5 milhares de reais.

Relacionando essa trajetória com a produção de petróleo é possível verificar que entre 2006 e 2011 a produção de petróleo no campo manteve um movimento de queda, mas mesmo assim o salário médio continuou estável. Já, em 2012 e 2013, mesmo com um aumento na produção, os salários médios diminuíram. Em 2015 a diminuição da produção foi de encontro a uma nova queda no valor do salário médio mensal.

Considerando a instalação de poços na área estudada, entre 2006 e 2008, o crescente incremento no número de novos poços coincide com o aumento no valor do indicador do 
EM

IBGE. Nos anos subsequentes, até 2015, a diminuição na implementação de poços apresenta uma semelhança com a diminuição do valor do salário médio mensal.

Diante das comparações entre a produção e o indicador econômico avaliado as informações adquiridas não permitem inferir uma influência direta entre esses dois fatores. Em relação a instalação de novos poços no campo, em dois momentos entre o período avaliado, as oscilações das variáveis apresentam semelhanças. Essa verificação conduz à indução de que pode existir alguma influência das atividades desenvolvidas no campo de petróleo com o avanço ou recuo do salário mensal médio.

Um elo que pode unir esses dois fatores é a oscilação da instalação de novos poços. É nessa etapa que são necessários os maiores investimentos e trabalhadores com alto nível de qualificação, diferentemente da atividade de apoio a produção já instalada, ocupada por pessoal de menor qualificação vinculados a empresas de pequeno porte (PIQUET, 2010).

\section{Empresas atuantes}

O Cadastro Central de Empresas realiza a sistematização de informações cadastrais e econômicas de empresas formalmente constituídas no país, inscritas no Cadastro Nacional da Pessoa Jurídica (CNPJ), da Secretaria da Receita Federal. A atualização desse Cadastro é realizada anualmente a partir das informações do IBGE, provenientes das pesquisas, por empresas, para as atividades de Indústria, Construção, Comércio e Serviços, bem como de registros administrativos do Ministério do Trabalho, como a RAIS. No indicador de "empresas atuantes" estão presentes informações das organizações formais ativas no país (IBGE, 2017). Os dados do indicador, da produção do campo e da instalação de novos poços retratam o panorama existente entre os anos de 2006 e 2015 (figura 4).

Figura 4 - Gráficos de empresas atuantes, produção do campo e instalação de poços entre 2006 e 2015.

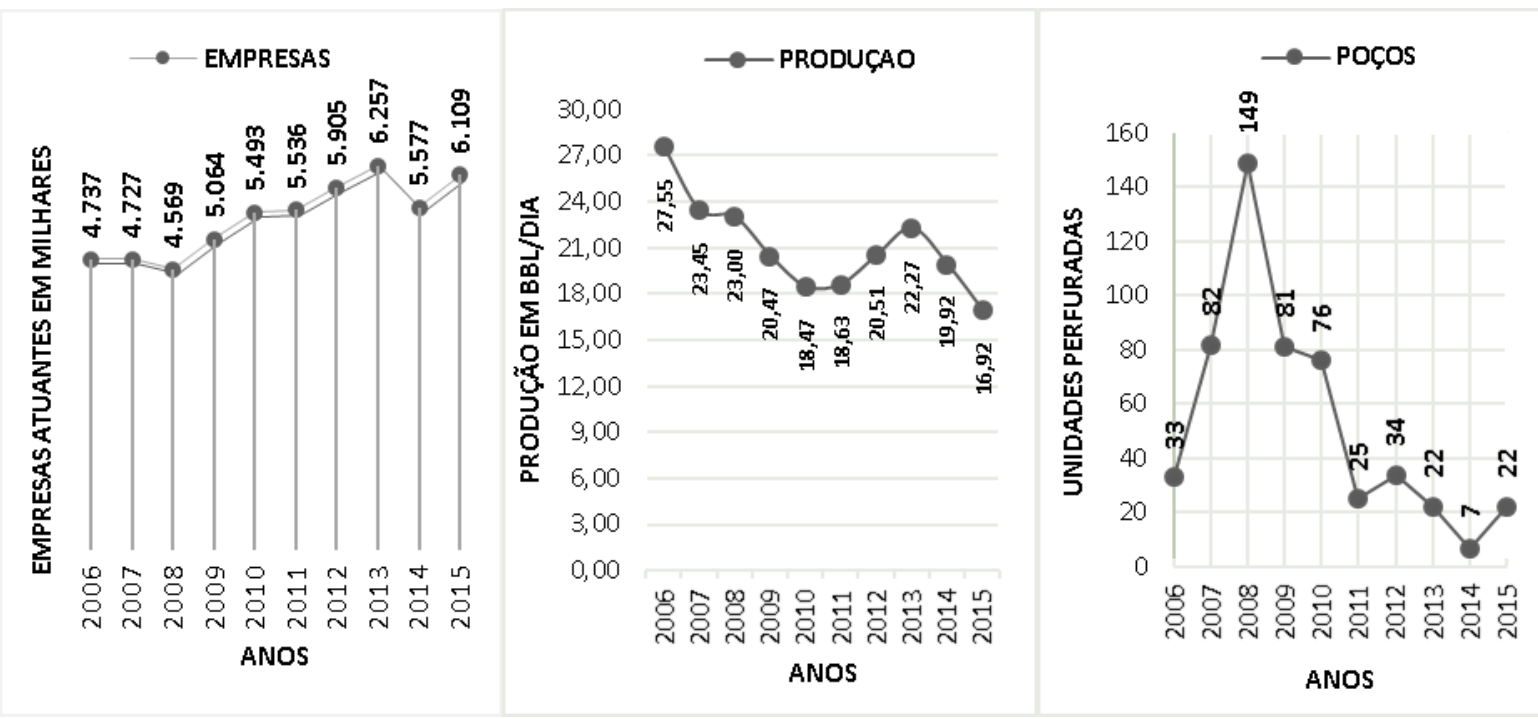

Fonte: Os autores, 2018.

Com base na comparação entre os gráficos da figura 4 é possível verificar que, entre 2006 e 2008, o número de empresas não apresenta oscilações importantes. A partir de 2009, até 2013, houve um incremento de 1.193 empresas ativas no município. A partir de 2014 o número caiu, mas em 2015, a quantidade de empreendimentos ativos oscilou positivamente, chegando a um nível semelhante ao verificado em 2013. 
EM

Em relação à produção do campo, entre 2006 e 2008 visualiza-se um movimento de constante diminuição. Entre 2010 e 2013 o nível produtivo de petróleo apresenta uma melhora, mas a partir de 2014 a curva volta a cair. No mesmo período, o número de empresas atuantes também evoluiu, chegando ao seu nível mais alto em 2013, com 6.257.

Em 2014, a produção petrolífera do campo apresentou novamente uma queda. Movimento semelhante ocorreu no número de empreendimentos ativos, mas, em 2015, mesmo com a produção continuando com oscilação negativa, o número de empresas ativa no município voltou a crescer.

Na relação entre a oscilação do número de empresas atuantes e a variação do número de poços instalados, entre 2006 e 2012, não pode ser inferida nenhuma semelhança entre flutuações das variáveis. Somente entre os anos de 2013 e 2015 o movimento da oscilação entre os itens analisados apresenta semelhança, mas distorcem da flutuação histórica dos anos anteriores. Sendo assim essa similaridade não pode induzir a ideia de uma influência direta.

Diante dessas inferências, a alteração da produção e da instalação de poços no campo provavelmente não influencia a oscilação no número de empresas instaladas no município. Essa condição pode estar relacionada com a pequena quantidade de empresas, com sede no município, envolvidas nos níveis de fornecimento da cadeia produtiva do petróleo (figura 5).

Figura 5 - Níveis de fornecimento da cadeia produtiva do petróleo.

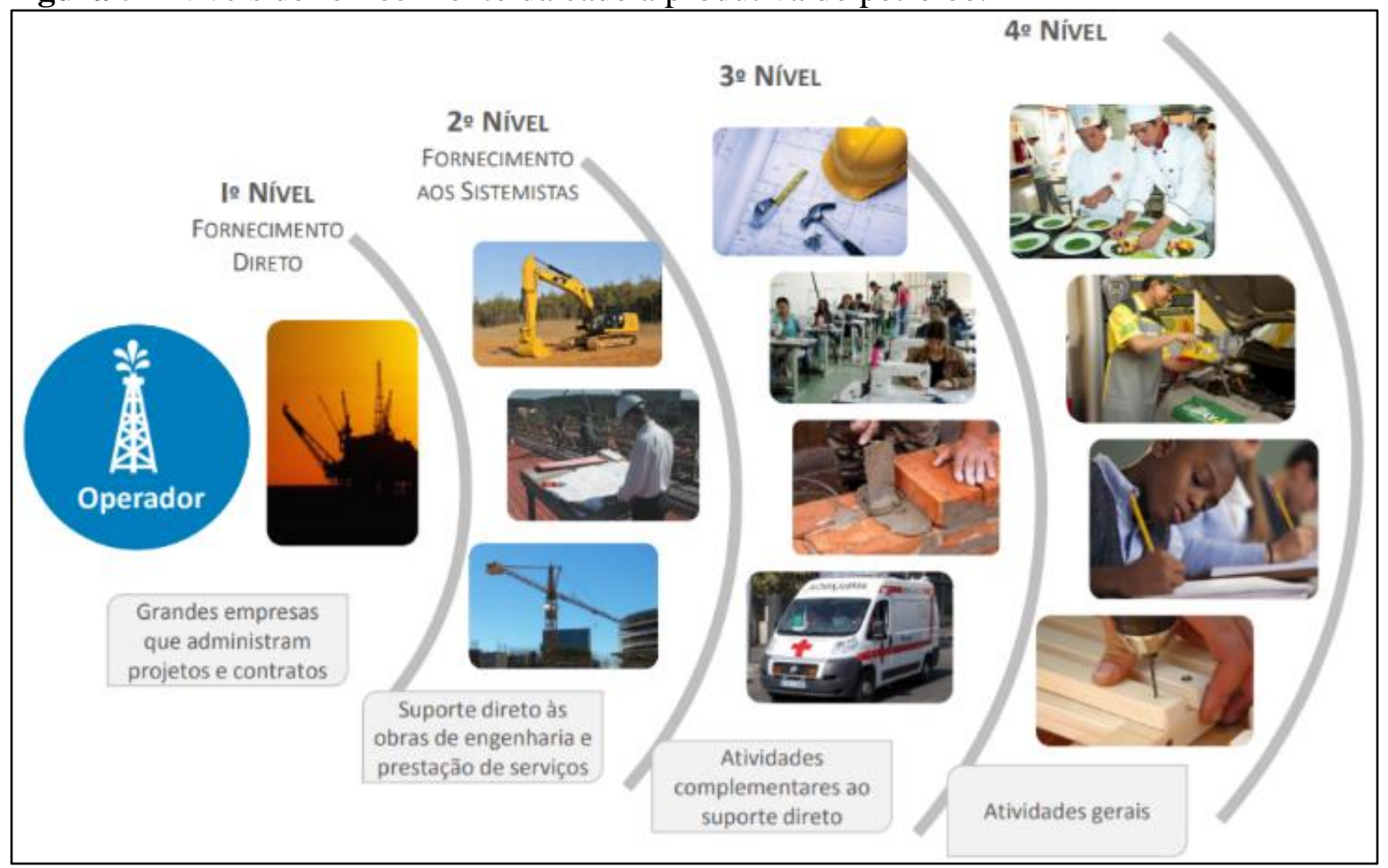

Fonte: Bezerra, 2017.

Considerando as informações presentes na figura 5, os fornecedores envolvidos no primeiro nível são grandes empresas que realizam a administração dos projetos e dos contratos das áreas de exploração. No segundo, as empresas envolvidas fornecem suporte direto na realização de obras de engenharia e na prestação de serviços. No terceiro nível, as empresas estão interligadas ao suporte direto. O último nível engloba uma diversidade maior de empresas que fornecem os produtos e serviços menos especializados da cadeia.

Para Bezerra (2017) é no quarto nível da cadeia que existe as maiores oportunidades de negócios para as micros e pequenas empresas do Rio Grande do Norte. No estado, existe 
EM

uma rede de empresas fornecedoras de bens e serviços para a cadeia produtiva de petróleo, intitulada RedePetro. Essa organização, em 2015 era composta apenas por 100 empresas (BEZERRA, 2071).

\section{Considerações finais}

Em Mossoró, a Petrobras instalou-se em 1980, mas somente em 1990 a empresa construiu sua atual sede. A partir de 1975, a estatal iniciou a perfuração de poços no município de Mossoró. Mas, somente em 1979 um poço perfurado pela CPRM para abastecer as piscinas de um hotel jorrou água misturada com petróleo. A partir disso, possibilitou a extração econômica de petróleo, em terra, no Rio Grande do Norte (ROCHA, 2005).

Como consequência disso, a região da cidade de Mossoró passou a se inserir dentro da cadeia produtiva do petróleo. A expansão da atividade ocasionou a intensificação da exploração de petróleo, o que contribuiu para a dinamização da economia local, pois por meio das atividades relacionadas à extração do petróleo empresas contribuíram para a movimentação de um fluxo de mão de obra, ocasionando demandas por novos serviços e por novas regiões habitacionais na cidade.

Nesse contexto, esta pesquisa buscou identificar possíveis relações entre as variações da produção e da instalação de poços no Canto do Amaro com indicadores econômicos do município, entre 1999 e 2015. Os dados e as análises da produção e da instalação dos poços foram comparados com os registros referentes ao recebimento de royalties, ao PIB per capita da população, ao número de pessoas ocupadas assalariadas, ao salário médio mensal e a quantidade de empresas ativas no município.

Através das comparações e análises realizadas foi possível verificar, em alguns períodos, similaridade nas oscilações da produção e da instalação de novos poços com os indicadores econômicos determinados. No entanto, essas semelhanças pontuais não são suficientemente consideráveis para exercerem influência direta nas flutuações dos indicadores durante o recorte temporal analisado.

Por fim, os resultados obtidos neste trabalho podem propiciar um apêndice metodológico para que futuros estudos possam identificar relações entre a atividade petrolífera e o conjunto de indicadores econômicos dos municípios utilizados pelo IBGE.

\section{Referências}

AGÊNCIA NACIONAL DE ENERGIA ELÉTRICA (ANEEL). Atlas de Energia Elétrica. 2. ed. Brasília: ANEEL, 2005. Disponível em: <http://www2.aneel.gov.br/aplicacoes/atlas/download.htm>. Acesso em: 23 mar. 2018.

AGÊNCIA NACIONAL DO PETRÓLEO, GÁS NATURAL E BIOCOMBUSTÍVEIS (ANP). Sumário Executivo Externo. Brasília: ANP, 2016.

Manual de cálculo dos royalties. Brasília, 2010. Disponível em: <http://www.anp.gov.br/images/Royalties-e-outrasparticipacoes/Manuais/Manual_de_Calculo_e_Distribuicao_de_Royalties.pdf>. Acesso em: 18 jul. 2018.

Sumário Executivo Externo. Brasília: ANP, 2017. 
EM

Resolução $n^{\circ}$ 749, de 21 de setembro de 2018. Brasília, Disponível em: $<$ http://pesquisa.in.gov.br/imprensa/jsp/visualiza/index.jsp?data=24/09/2018\&jornal=515\&pa gina=79\&totalArquivos=170> . Acesso em: 24 set. 2018 .

ALBERINI, Jean Carlos. Estratégia para o desenvolvimento da cadeia produtiva de petróleo e gás no Paraná. 2011 Dissertação (Mestrado Profissional em Desenvolvimento Econômico) - Universidade Federal do Paraná, Curitiba. Disponível em: < https://acervodigital.ufpr.br/handle/1884/25710?show=full >. Acesso em: 28 mar. 2018.

BEZERRA, Paulo Ricardo Cosme. Mensuração da ecoeficiência das micro e pequenas empresas da cadeia produtiva do petróleo e gás potiguar, com uso da taxonomia CE7. 2017. 167 f. Tese (Doutorado) - Curso de Engenharia de Petróleo, Universidade Federal do Rio Grande do Norte, Natal, 2017. Disponível em: <https://repositorio.ufrn.br/jspui/bitstream/123456789/24150/1/PauloRicardoCosmeBezerra TESE.pdf>. Acesso em: 02 abr. 2018.

BRAUNS, Bianka et al. Viabilidade técnica e econômica na exploração de petróleo em campos maduros. Uma porta para a indústria nacional. In: Congresso nacional de excelência em gestão, 6., 2010, Niterói. Anais... . Niterói: Congresso Nacional de Excelência em Gestão,

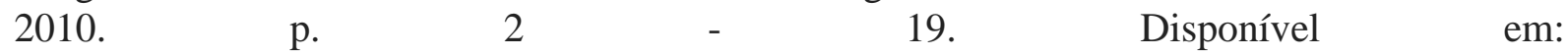
<http://www.inovarse.org/sites/default/files/T10_0233_1313.pdf>. Acesso em: 05 jun. 2018.

FARIAS, Robson Fernandes de. Introdução à química do petróleo. Ciência Moderna; Rio de Janeiro, RJ: 2008.

GEREFFI, Garry; FERNANDEZ-STARK, Karina. Global Value Chain Analysis: A Primer. Center on Globalization, Governance and Competitiveness, 2011.

GURGEL, Cinthya Antonia Vieira; QUEIROZ, Gabriela Barros de; SANTOS, Esaull Luciano Soares Campos dos; GALVÃO, Maria Luíza Medeiros de. Impactos de extração do petróleo (óleos e gás) no Rio Grande do Norte, na região do Alto do Rodrigues/RN. Holos, Ano 29, v. 3, 2013.

INSTITUTO BRASILEIRO DE GEOGRAFIA E ESTATÍSTICA (IBGE). Estatísticas do cadastro central de empresas. Rio de Janeiro: IBGE, 2017. Disponível em: <https://biblioteca.ibge.gov.br/visualizacao/livros/liv100618.pdf>. Acesso em: 28 mar. 2018.

$\begin{array}{llccc}\text {. Indicadores IBGE: Pesquisa } & \text { Industrial Mensal } & \text { Emprego e Salário } & \text { (PIMES). } \\ \text { Brasília: } & \text { IBGE, } & 2015 . & \text { Disponível } & \text { em: }\end{array}$ <ftp://ftp.ibge.gov.br/Industrias_Extrativas_e_de_Transformacao/Pesquisa_Industrial_Mensal _de_Emprego_e_Salario/Fasciculo_Indicadores_IBGE/pimes_201512caderno.pdf>. Acesso em: 28 mar. 2018.

. Série Relatórios Metodológicos: Produto Interno Bruto dos Municípios. Rio de Janeiro: $\quad 2004 . \quad$ Disponível em: <https://biblioteca.ibge.gov.br/visualizacao/livros/liv4547.pdf>. Acesso em: 28 mar. 2018. 
EM

QUESTÃO

V.13 N. $03 \bullet 2020$

pág. 9-32

JESUS, Fernanda Delgado de et al. A Nova Metodologia de Cálculo de Royalties. Boletim de Conjuntura FGV Energia. Rio de Janeiro, p. 4-11. jul. 2017. Disponível em:

$<$ https://fgvenergia.fgv.br/sites/fgvenergia.fgv.br/files/coluna_opiniao_julho_-

_mariana_cals.pdf>. Acesso em: 06 jul. 2018.

PETROBRAS, Agência. Petrobras bate novos recordes de produção de petróleo e gás. 2014. Disponível em:

$<$ http://www.agenciapetrobras.com.br/Materia/ExibirMateria?p_materia=976757>. Acesso em: 25 mar. 2018. (PETROBRAS, 2014)

PIQUET, Rosélia Périssé da Silva. A CADEIA PRODUTIVA DO PETRÓLEO NO BRASIL E NO NORTE FLUMINENSE. Revista de Desenvolvimento Econômico, Salvador, v. 12, n. 22, p.19-27, dez. 2010. Disponível em: <https://revistas.unifacs.br/index.php/rde/article/view/1221/1175>. Acesso em: 19 set. 2018.

ROCHA, Aristotelina Pereira Barreto. Expansão Urbana de Mossoró: Período de 1980 a 2004. Natal: Coleção Mossoroense, 2005. 